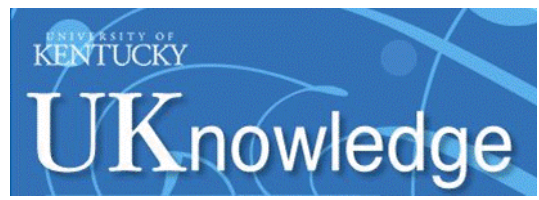

University of Kentucky

UKnowledge

Rural \& Underserved Health Research Center

Publications

Rural \& Underserved Health Research Center

$11-2019$

\title{
Hospital Closures and Short-Run Change in Ambulance Call Times
}

Sookti Chaudhary

University of Kentucky, sookti.chaudhary@uky.edu

Alison F. Davis

University of Kentucky, alison.davis@uky.edu

Kenneth R. Troske

University of Kentucky, ktroske@uky.edu

SuZanne Troske

University of Kentucky, s.troske@uky.edu

Follow this and additional works at: https://uknowledge.uky.edu/ruhrc_reports

Part of the Health Services Research Commons

Right click to open a feedback form in a new tab to let us know how this document benefits you.

\section{Repository Citation}

Chaudhary, Sookti; Davis, Alison F.; Troske, Kenneth R.; and Troske, SuZanne, "Hospital Closures and Short-Run Change in Ambulance Call Times" (2019). Rural \& Underserved Health Research Center Publications. 19.

https://uknowledge.uky.edu/ruhrc_reports/19

This Report is brought to you for free and open access by the Rural \& Underserved Health Research Center at UKnowledge. It has been accepted for inclusion in Rural \& Underserved Health Research Center Publications by an authorized administrator of UKnowledge. For more information, please contact UKnowledge@lsv.uky.edu. 


\section{Z A Institute of Labor Economics}

Initiated by Deutsche Post Foundation

\section{DISCUSSION PAPER SERIES}

IZA DP No. 12797

\section{Hospital Closures and Short-Run Change} in Ambulance Call Times

Sookti Chaudhary

Alison Davis

Kenneth Troske

SuZanne Troske 


\section{Z A Institute of Labor Economics}

Initiated by Deutsche Post Foundation

\section{DISCUSSION PAPER SERIES}

IZA DP No. 12797

\section{Hospital Closures and Short-Run Change in Ambulance Call Times}

\section{Sookti Chaudhary}

University of Kentucky

\section{Alison Davis \\ University of Kentucky}

\author{
Kenneth Troske \\ University of Kentucky and IZA
}

\author{
SuZanne Troske \\ University of Kentucky
}

Any opinions expressed in this paper are those of the author(s) and not those of IZA. Research published in this series may include views on policy, but IZA takes no institutional policy positions. The IZA research network is committed to the IZA Guiding Principles of Research Integrity.

The IZA Institute of Labor Economics is an independent economic research institute that conducts research in labor economics and offers evidence-based policy advice on labor market issues. Supported by the Deutsche Post Foundation, IZA runs the world's largest network of economists, whose research aims to provide answers to the global labor market challenges of our time. Our key objective is to build bridges between academic research, policymakers and society.

IZA Discussion Papers often represent preliminary work and are circulated to encourage discussion. Citation of such a paper should account for its provisional character. A revised version may be available directly from the author.

\section{ISSN: 2365-9793}

IZA - Institute of Labor Economics 


\title{
ABSTRACT
}

\section{Hospital Closures and Short-Run Change in Ambulance Call Times*}

We measure one aspect of how access to emergency care through ambulance services changes for patients when a hospital closes. We empirically estimate the time needed to transport a patient to an emergency department in an ambulance in the period immediately after the hospital closes. We find urban patients in zip codes where a hospital closes have a small change in transportation time, where rural patients average an estimated 15.7 additional minutes - a $46 \%$ increase compared to the year before the closure. This increase is primarily the result of an almost 100 percent increase in the time it takes to transport a patient from the location of the incident to the hospital. The impact on rural Medicareeligible patients is even larger. We find no change in the time it takes ambulances to arrive at an incident and only a small change in the time spent at the scene.

JEL Classification: $\quad|11| 14,, \mid 18, \mathrm{R} 10$

Keywords: $\quad$ ambulance, hospital closure, access to care, rural vs urban

\author{
Corresponding author: \\ Kenneth Troske \\ Gatton College of Business and Economics \\ University of Kentucky \\ Lexington, KY 40506-0034 \\ USA \\ E-mail: ktroske@uky.edu
}

\footnotetext{
* The authors thank Clay Mann and Mengtao Dai of the National Emergency Medical Services Information System, through the University of Utah, for their help with understanding and acquiring the ambulance data, and seminar participants at the University of Kentucky, the North American Regional Sciences Council annual conference and the Institute for Labor Economics (IZA) seminar series, Nathan Wozny and Carlos Lamarche for helpful comments. This project was supported in part by the Federal Office of Rural Health Policy (FORHP), Health Resources and Services Administration (HRSA), U.S. Department of Health and Human Services (HHS) under cooperative agreement \# U1CRH30041. FORHP also provided valuable comments on this work. Kenneth Troske completed some of the work on this project while visiting IZA and he thanks them for financial support. The information, conclusions and opinions expressed in this document are those of the authors and no endorsement by FORHP, HRSA, HHS, or the University of Kentucky is intended or should be inferred.
} 


\section{Introduction}

When a hospital closes in a community the emergency department (ED), in general, also closes, so patients in the community must travel to a hospital further away to receive treatment. This has led to speculation that people needing emergency treatment must spend more time in an ambulance while being transferred to the $\mathrm{ED}$, which, in turn, could result in a decline in health outcomes. Between 2011 and 2014, 91 hospitals closed in the United States, with nearly half of these closures being hospitals located in rural areas. While the number of closures is small relative to the total number of hospitals (in 2018 there were 4,840 nonfederal hospitals in the U.S.), a closure could still have a significant impact on people living near the hospital that closes. In addition, the impact could be particularly severe for individuals living in rural communities since, for many rural residents, being transported to the next closest hospital could result in a significant increase in the time spent in an ambulance. Unfortunately, we can only speculate on the effect of a hospital closure on patient travel time since, as far as we are aware, there is no existing research examining the impact of a hospital closure in an area on patient travel time to an ED in an ambulance.

In response to this lack of evidence, we examine how the time patients spend in an ambulance changes immediately after a hospital near them closes. Using data on hospital closures from 2011 to 2014 and ambulance trip times from 2010 to 2015, we compare how the travel time to a hospital changes for patients living in a zip code where a hospital closes with changes in travel time for patients living in a statistically similar zip codes where a hospital has not closed. We also compare changes in travel times separately for patients living in rural and urban zip codes as well as for Medicare-eligible patients.

In our main specification we find that people living in urban areas experience no significant increase on average in travel time to an ED in the year after a hospital closes in the zip code where they live. Although in subsequent analysis we find evidence suggesting that individuals living in urban areas do experience a relatively small increase in total time and transport time in an ambulance, this change occurs prior to the hospital closing. In contrast, patients living in rural zip codes experience an estimated 15.7 additional minutes in the total time it takes from ambulance dispatch to arriving at an ED in the year after a hospital closes in their zip code-a forty-six percent increase compared to the year before the closure which is primarily due to a 
fourteen minutes or a ninety-six percent increase in average transport time in the year after a hospital closes relative to the transport time in the year before the hospital closes. We find no significant change in the time it takes the ambulance to get to the scene, or in the time spent at the scene. This is what one would expect if the only thing that changed was the location of the closest hospital. We also find that the impact on Medicare-eligible patients living in rural areas is even larger. We find no evidence suggesting that these short-run changes are the result of changes in the behavior of ambulance companies or individuals.

The lack of data tying patient health outcomes directly to the total time it takes to transport them to a hospital, as well as the inconsistent results from previous studies examining this issue, makes it difficult to draw strong conclusions on the impact of a hospital closure on the wellbeing of people in a community. However, given the size of the impact we find, particularly for individuals living in rural communities and for Medicare-eligible patients, it seems likely that a hospital closure has a detrimental effect on individuals living near the hospital. Our results also demonstrate the importance of developing data that would allow researchers to better measure the impact of the quality of ambulance services in a region on health.

In the next section of the paper we review the literature on how changes in ambulance call times and distance might impact patient outcomes. In Section III, we discuss the data that form the foundation of our analysis and how we combine data from various sources for the final data set used in our analysis. In Section IV, we discuss our empirical methodology. We discuss our results in Section V and present our conclusions in Section VI.

\section{Review of Previous Literature}

We begin our review of the literature by examining how the time and distance a patient must travel changes with a hospital closure. We follow this with a discussion of the literature on how patients' choices about how to get to a hospital, or even whether to go to a hospital, changes after their local hospital closes. Next we turn to a discussion of how ambulance services respond to a hospital closing. We then explore the literature on how patient health outcomes change with an increase in the time it takes to get to an ED. Finally, we briefly discuss the literature on the factors leading to a hospital closure. 
Given that our data only cover the changes that occur in the year after a hospital closes, we focus here on the short-run changes. Obviously, as both patients and ambulance services adapt to the hospital closing, possibly by relocating, these affects could diminish over the long run.

\section{Distance and Time}

It is expected that in most instances after a hospital closes a patient would be redirected to a different ED located farther away from the incident location than the hospital that closed, which is assumed to increase time to care. When examining how a hospital closing changes the distance and time a patient needs to travel to the nearest hospital existing studies find little change in urban areas but larger changes in rural areas. ${ }^{3}$ Hsia et al. (2012) study patients living in urban areas in California between 1999-2009 and find that most patients experience no increase in distance transported after a hospital closes. Kaufman et al. (2016) examine rural hospital closures and find that the next closest hospital averaged 14.4 miles further away. Samuels et al. (1991) find for hospitals that closed in 1989, the increased travel time by any means to the next open hospital was 3.5 minutes for urban hospitals and 18.7 minutes for rural hospitals.

\section{Patient Choice}

If increased distance or time resulting from a hospital closing is viewed as an increase in cost by the patient, the patient could choose not to go to an ED and instead receive medical attention at an urgent care center, go see their primary care doctor, or choose not to receive any treatment, which would lead to a decline in the demand for ambulance services and perhaps an average decrease in the time spent in an ambulance for patients who continue to use ambulance services. Buchmueller, Jacobson, and Wold (2006) examine hospital closures in Los Angeles County and find that the increased distance from an ED led patients to shift away from an ED as their "usual source of care" to a primary care physician. Lee et al. (2015) predict that if the nearest ED closes then there will be an increase in the volume of patients at the next closest ED. They found about 20 percent of the patients predicted to show up at the next closest ED did not. While not specifically examined in their paper, the authors speculate patients sought medical attention in other healthcare facilities and not at an ED.

\footnotetext{
${ }^{3}$ The patient will likely be transported to the next closest ED per their health insurance. For Medicare beneficiaries, federal reimbursement rules require an ambulance to take a patient to the closest facility which has the needed health resources for the patient (U.S. Centers for Medicare and Medicaid Services, 2016). According to the Kaiser Family Foundation, in 2012 all states required Medicaid beneficiaries to be transported to the nearest hospital as well (The Henry J. Kaiser Family Foundation, 2012).
} 
When the hospital closed in Haywood County, Tennessee, the demand for ambulance services increased as some patients resorted to receiving emergency care from the ambulance service and then refused to be transported to the hospital because they found it too burdensome to find transportation back home from the hospital (Goldstein, 2017). If what is described in this article occurs regularly, this could lead to fewer ambulance trips to an ED on average in rural communities.

\section{Change in Ambulance Services}

The supply of ambulance services could change when an ED closes leading to changes in total response times. One reason is the availability of the ambulance could change as ambulances must travel further to the next closest ED resulting in an increase in the probability of that vehicle and crew being unavailable for the next emergency call, leading to an increase in response times. However, Mueller et al. (2016) find very remote areas have fewer delays on average in all parts of the ambulance call times than the average of times in urban, suburban and rural areas (non-remote areas).

For urban areas, a closed hospital could mean overcrowding at the next closest ED, which would cause ambulances to be diverted to another ED even farther away further increasing the patient's time in an ambulance. Over a 7-year period in Los Angeles County, Sun et al. (2006) found when a hospital closed the next closest ED experienced a short-term surge in crowding over the following four months, leading to ambulance diversions. However, after this period the EDs adjusted to the change in demand and there were fewer incidences of overcrowding.

Doyle, Graves, Gruber, and Kleiner (2015) examine dispatch patterns among ambulance services in small geographic areas and provide evidence that services tend to prefer certain hospitals. If the preferred hospital closes, time in an ambulance could decrease if the new "preferred" hospital is closer. In addition, by the time a hospital closes it may be the patients and ambulance services have adjusted their behavior ahead of time in anticipation of the closer hospital closing. This could be particularly true if the number and quality of medical services offered at the closing hospital declines prior to its closing (Samuels et al., 1991). In this case, by the time the hospital closes we would not observe any change in ambulance call times.

When the number of insured patients increases in an area this could lead to an increase in the demand for ambulance services. Courtemanche et. al (2019) found when there was increased demand for ambulance services due to more patients being insured under the Affordable Care 
Act (ACA), there was a greater than two minute or twenty-four percent increase in the time an ambulance took to arrive on the scene of a motor vehicle accident in urban areas. They also found an eight to nine percent increase in the number of trips provided. In the short run, the authors found the additional demand for ambulance services led to an increase in response times.

\section{Patient Health Outcomes}

Ultimately, the important question is how additional time required for an ambulance call affects patient health. Previous studies examined the relationship between changes in distance and time and patient outcomes for patients suffering from many time-sensitive diseases including acute myocardial infarction (AMI), cardiac arrest, asthma and chronic obstructive pulmonary disease (COPD) and trauma injury. The patient outcome primarily examined is mortality. Most previous studies focused on the time to scene - the time from dispatch to the incident locationas the measure of response time. This is likely because the National Fire Protection Association (2016) sets a standard of eight-minute time to scene for advanced life support (ALS) ambulance calls. The standard is also typically part of ambulance service performance assessment.

Several studies found no relationship between time to scene and mortality for the diseases examined in their studies (Newgard et al., 2010; Pons et al., 2005). Blackwell, Kline, Willis, and Hicks (2009) analyzed trauma injury calls comparing the outcomes of a treatment group of patients for whom the time to scene was greater than 11 minutes with a randomly sampled control group for whom the time to scene was less than 11 minutes. They found no significant impact of time to scene on patient outcomes. In an urban setting, Pons and Markovchick (2002) examined whether an 8-minute EMS response time goal had any impact on mortality for trauma injury and found no effect in areas that implemented the 8-minute goal.

Other studies found a modest increase in survival to hospital discharge with a decrease in time to scene for cardiac arrest patients (Nichol et al., 1996; Pell et al., 2001). Pons et al. (2005) found what is most important for patients with cardiac arrest is the time to electrical defibrillation and not the response time of the ambulance. Nichol et al. (1996) found a two-tier system of care including early access to care, early defibrillation and early ALS-level EMS response were most important for cardiac arrest patients and not the distance to the hospital. Wilde (2013) points out the potential endogeneity of the time to scene variable because of the discretion of ambulance drivers who decide how quickly to arrive at the scene based on the reported severity of the case. Failing to consider such endogeneity may result in finding no 
significant relationship between time to scene and mortality. Once she accounts for this endogeneity Wilde finds a strongly significant impact of time to scene on mortality for diseases other than cardiac arrest, AMI and trauma injury.

Researchers have also examined the impact of increasing the time it takes to transport the patient to the hospital and find the impact largely depends on the emergent medical condition. Nicholl et al. (2007) studied transport time and found that a ten percent increase in transport time led to a one percent increase in mortality for all patients except those with cardiac arrest. Jena, Mann, Wedlund, \& Olenski (2017) examined the change in mortality of Medicare-aged patients who suffered from AMI or cardiac arrest and took an ambulance to a hospital when a marathon was being held in a city compared to patients' transport time to the hospital when a marathon was not occurring. They found that patients transported during a race were in an ambulance 4.4 minutes longer on average, which was a 32.1 percent increase in transport time, and resulted in the five-week mortality rate increasing from 24.9 percent to 28.2 percent. Buchmueller et al. (2006) found when a hospital closed in Los Angeles County between 1997-2003 one additional mile traveled by patients (not necessarily in an ambulance) experiencing AMI led to a 6.5 percent increase in the number of deaths. For accidents caused by a variety of unintentional causes such as motor vehicles, falls and poisonings, the additional mile led to 11-20 percent increase in the number of deaths.

Some studies have found no relationship or improved health outcomes with longer trips, again, depending on the patient's condition. Newgard et al. (2010) estimated the impact of time spent at the scene and transport time on patient outcomes and found for trauma injury there was no association between the various portions of ambulance call times and mortality. Buchmueller et al. (2006) argued closed hospitals tend to be small, financially distressed, facilities with fewer specialty services so patients could experience an increased transport time in an ambulance but see improved health outcomes because of the higher quality care they receive from the next closest facility.

Sanghavi et al. (2015) argue that, except for patients with AMI, patient outcomes improve when ambulance drivers or paramedics spend less time at the scene treating patients and instead focus on transporting the patient to an ED as quickly as possible. McCoy et al. (2013) show increased odds of mortality among severely injured trauma patients with scene times greater than 
20 minutes where patients with less severe injuries showed no increased odds of mortality with longer scene times.

In the end, studies examining the impact of changes in the time to scene or changes in transport time do not find a consistent impact on patient health - although most argue for faster services. There are many variables such as the emergent medical condition of the patient which can affect the time of an ambulance call and its effect on patients' health outcomes.

Factors Accounting for Hospital Closures

Research into why hospitals close show that declining Medicare caseloads and declining population in an area are both correlated with the probability that a hospital closes (e.g. Williams, D., Hadley, J., \& Pettengill, J., 1992; Kaufman et al., 2016). Areas where hospitals close also have higher rates of unemployment, larger shares of black and Hispanic residents and tend to be closer to another hospital (e.g. Thomas, S. R. et al., 2015; Ko, M. et al., 2014). Hospitals that close are also less efficient than other hospitals in the area (Buchmueller et al., 2006). This research finds that similar factors account for hospital closures in rural and urban areas.

\section{Data}

\section{Ambulance Call Data}

To conduct our analysis, we access data on ambulance calls from the National Emergency Medical Services Information System (NEMSIS), which is a national repository of ambulance call data (Mann, Kane, Dai, \& Jacobson, 2015; NEMSIS, 2016). The data contain individual patient, incident, and ambulance service data for a single 9-1-1 call involving an emergency transport to a hospital. The data are a convenience sample, meaning reporting of the data is not mandatory and compliance varies by state by year. In 2015, 47 states and Washington, DC reported data to NEMSIS. ${ }^{4}$ Four states, Delaware, Massachusetts, Ohio, and Texas reported no data in any year.

For each call we know the patient's age and gender. The exact location of the incident is deidentified due to NEMSIS confidentiality restrictions. However, NEMSIS assigns the 2003 USDA Urban Influence Codes (UIC) to the area of the zip code of the incident location. The

\footnotetext{
${ }^{4}$ Not every region in each state reports data to NEMSIS.
} 
geographic areas are urban (UIC1,2), suburban (UIC3,5), rural $(4,5,8,9)$, or wilderness (UIC 7,10 11,12) (Newgard et al., 2010). We label calls as rural if they are rural or wilderness, and as urban if they are urban or suburban. We also know the Census region and division.

For the ambulance services, we know the organizational type of the service: fire department, governmental units not associated with a fire department, hospital-based, nonprofit organizations in the community, and for-profit, private services. Hospital-based ambulances may be for-profit or non-profit services depending on the management of the hospital. We exclude from our data transports from paramedic intercepts, specialty care or air transports. ${ }^{5}$ The data also indicate the highest medical staff available to provide care on the ambulance and whether the staff are volunteers or non-volunteers.

Ambulance personnel report the duration of different portions of the service: time to the scene of incident location, time at the scene or scene time and transport time from the scene to the ED. The total response time is the summation of the three separate times. In the NEMSIS data, there are some zero, negative, as well as very large positive times. According to NEMSIS, one of the main reasons for these errors is keying in the wrong date and/or time. NEMSIS also reports that when an agency does not report a time the system may automatically give it a default time which can result in large negative or positive times. ${ }^{6}$ For some calls, the agencies report the same time for different call time variables which results in a response time of zero. A response time of zero can also occur when a call is cancelled. In order to lessen the amount of measurement error, we drop observations with total response times of less than ten minutes and greater than 120 minutes. Since total response time is the sum of time to scene, scene time, and transport time, each of these times is also less than 120 minutes. We drop all records with missing transport time. We know the day of the week and the hour of the day for the ambulance call. From this we create indicators for weekend, weekday, morning rush hour (6:00-10:00 AM) and evening rush hour (4:00-8:00 PM).

In our analysis, we focus on time in the ambulance as opposed to distance traveled because distance is not in the data we received from NEMSIS. However, response time is the most common measure in service agreements and contracts between EMS companies and

\footnotetext{
${ }^{5}$ A paramedic intercept is when the ambulance that transports the patient to the hospital is different than the ambulance that originally arrived on the scene.

${ }^{6}$ This information came from email correspondence with the NEMSIS staff in August 2018.
} 
municipalities (David \& Brachet, 2011), so this is not a severe limitation. We assume while ambulance services can vary in quality of service delivery, there is no major change in the performance of the ambulance service between the year before the hospital closes and the year after. Likewise, we assume there are no major changes in the 9-1-1 response system or other unobserved characteristics of the ambulance service around the time when the hospital closes. Hospital Data

We obtain data on confirmed hospital closures from the University of North Carolina Cecil G. Sheps Center for Health Services Research and the Health Resources and Services Administration (HRSA) for the period 2010-2015. ${ }^{7}$ These data indicate that 91 hospitals closed during this time period. Figure 1 shows all hospital closures from 2011-2014. Hospital closures in rural areas are shown as diamonds. The states with the most closures were Texas (20), California (7), and Alabama (7).

We obtain location information for all hospitals in the U.S. from the Hospital Compare data available from the Centers for Medicaid \& Medicare Services (CMS) (U.S. Centers for Medicare and Medicaid Services, 2010-2016a). These data contain yearly information on over 4,000 Medicare-certified hospitals across the country including acute care and critical access hospitals. ${ }^{8}$ We merge the Hospital Compare data with the hospital closure data. ${ }^{9}$ The resulting data have all Medicare hospitals from 2011-2014 with an indicator if a hospital closed. This file contains time-invariant hospital characteristics such as number of beds gathered from the CMS Provider of Service (POS) file (U.S. Centers for Medicare and Medicaid Services, 2010-2016b) and the zip code where the hospital is located.

Finally, the hospital data are summarized at the zip code level and include information on the number of hospitals, number of hospital closures, and number of beds for each year of the data. There are approximately 4,300 zip codes per year with at least one hospital. No zip code has more than one hospital closure in a year. We drop zip codes where reported population is zero or missing. ${ }^{10}$ We then merge in demographics of residents living in the zip code: population,

\footnotetext{
${ }^{7}$ The rural hospital closures can be found at http://www.shepcenter.unc.edu/ accessed December 12, 2017. We received a list of urban and rural closures per a data request from HRSA on January 9, 2017.

${ }^{8}$ Ninety-eight percent of these types of hospitals supplied complete data to CMS (U.S. Government Accountability

Office, 2006). This count does not include long-term care, rehabilitation or psychiatric hospitals.

${ }^{9}$ When we merge the hospital closure file with the Hospital Compare file all but five closed hospitals match.

${ }^{10}$ An example of this is a university hospital with its own business zip code.
} 
population density, median household income, median age of adults, percent of population 75 years old and older. ${ }^{11}$ For each zip code, we assign a hospital service area (HSA) and add HSAlevel population to the data. ${ }^{12}$

Because not all areas of the country report ambulance service data to NEMSIS, we only keep data on hospital closures located in an area that reports data to NEMSIS in the year the hospital closed, which leaves us with data on fifty-one hospitals that closed from 2011-2014. ${ }^{13}$ Table 1 compares the hospital closures selected for our study with all hospital closures. The closures in our study are more rural than all closures and on average larger. In our closures data there is a higher percentage of hospitals closing in the Northeast. Despite not being able to include hospital closures in Texas, we still have a large proportion of closures in the South (52 percent).

\section{Selection of Comparison Zip Codes}

While we have data by zip code for over 4,000 hospitals in the U.S., as well as for the 51 hospitals that closed, we are unable to match these data directly to data on ambulance calls from NEMSIS because, to maintain confidentiality, the only location data on ambulance calls that NEMSIS releases is Census region, division and whether the call occurs in a urban or rural area. However, NEMSIS was willing to provide us with a file of all ambulance calls over a given period for a specified set of zip codes that we chose. In choosing a set of zip codes, we start with the zip code and year where a hospital closed. In our analysis we want to compare changes in the length of ambulance calls in a zip code from the year prior to the year after a hospital closure. We also want to compare these changes to changes in the length of ambulance calls between the same years in statistically similar zip codes where a hospital has not closed.

To choose our sample of statistically similar zip codes, we use a technique called propensity score matching (Heinrich, Mueser, Troske, Jeon, \& Kahvecioglu, 2013). Using data on all zip codes with at least one hospital, we start by estimating a logit model to estimate the probability that a hospital closes in the zip code in a given year controlling for the characteristics of the zip code. The characteristics included in the estimation are, the log of population density, the

\footnotetext{
${ }^{11}$ Demographic data are from the American Community Survey 2009-2013 5-year estimates (U.S. Census Bureau, 2013).

12 "HSAs are created to indicate the local market for a hospital. An HSA contains groups of zip codes containing residents that are likely to go to that hospital when they require hospitalization. (The Darmouth Institute for Health Policy and Clinical Practice, 2017).

${ }^{13}$ The information on which states are reporting to NEMSIS is from the NEMSIS website and numerous presentations made by NEMSIS on the state of the database.
} 
proportion of the population 75 years old or older, median household income and its square, as well as the log of the population in the HSA and Census region that contain the zip code. We estimate separate logit models for every year of our data, essentially estimating the probability that a zip code contains a hospital that closes in that year, conditional on the controls included in the regression. We then keep the estimated probability and convert it into a log odds ratio. Using the estimated log odds ratio we then match the zip code where there is a hospital that closes to all zip codes where a hospital has not closed with a log odds ratio within 0.008 of the log odds ratio of the zip code where the hospital has closed-what is referred to as many-to-one caliper matching. ${ }^{14}$ We chose the caliper of 0.008 because it allows the most matches while being sufficiently small to ensure that the matched zip codes have similar characteristics. ${ }^{15}$ One benefit of the many-to-one matching is that it increases the number of zip codes we are submitting to NEMSIS. We refer to zip codes where hospitals closed as our treated zip codes and the matched zip codes as our comparison zip codes.

Once we complete the matching, we check the quality of the matches using a balancing test. This involves comparing the difference in the mean value of the control variables between the treatment and comparison zip codes. We use a t-test to determine if no more than five percent of the variables are statistically significantly different at the 99 percent level. If there are more variables that are different then we adjust the specification and size of the caliper. The process described above passes the balancing test. In addition, we can find matches for all treated zip codes but one, which we drop, helping to ensure that the comparison zip codes are comparable to the treated zip codes.

The effectiveness of the propensity score procedure to produce an appropriate sample of comparison zip codes rests on the assumption that the probability that a zip code receives the treatment is independent conditional on the observable controls - what is known as the conditional independence assumption. While it is impossible to formally test this assumption, the balancing test does help assure it holds. We also believe we have a reasonable set of control

\footnotetext{
${ }^{14}$ We match without replacement by year, but with replacement across years, so the same zip code can be matched to more than one zip code with a hospital closure in multiple years.

${ }^{15}$ One reason for using many-to-one caliper matching is that it produces more precise impact estimates by using all available data and not throwing out similar matches (Mueser et al., 2007). The downside to multiple matches is that it can produce a bias estimate resulting from using poor matches (Heinrich et al., 2010). However, our caliper is small enough to limit poor matches, so we believe the multiple matches helps improve the efficiency of our resulting estimates more than any bias that is introduced.
} 
variables that help determine the likelihood a zip code contains a hospital that closes in a given year. Finally, the empirical method we use to estimate the impact of a hospital closure on the length of an ambulance run, which we describe in the next section, was chosen to further ensure that we are comparing statistically similar zip codes.

\section{Sample Construction}

The outcome from our matching is a list of treated and comparison zip codes for the years 2011-2014. We provide this file to the staff managing NEMSIS who returned to us data on all ambulance calls one calendar year before and the year after a hospital closed. There are no zip code identifiers in the returned data. We only know whether the incident which resulted in the ambulance run occurs in a treated or comparison zip code. The ambulance may transport patients to hospitals either within or outside the zip code. Of the total number of zip codes sent to NEMSIS thirteen percent did not match so we have no ambulance call data for these zip codes. We do not believe that dropping these zip codes biases our results, as the missing matches are due to non-reporting to NEMSIS which appears independent of ambulance call times. The final file has 13.8 million ambulance calls for the years 2010-2015.

In the final data set, for each zip code we have data on ambulance calls in the year prior to the match year and the year after the match year, where match year refers to the year a hospital closes in the treated zip code. In Table 2, we report patient, ambulance service, and incident characteristics for our final data set where each observation is one ambulance trip. In our final dataset we have 62,163 ambulance calls in our treated zip codes and 13.7 million in our comparison zip codes. The patients being transported are on average 56 years old and 55 percent are female. The patients in rural areas are almost three years older on average than those in the urban areas. The organizational type servicing the plurality of calls in our data are ambulances that are part of fire departments (26 percent of calls), followed by government non-fire ambulances ( 23 percent) and ambulances run by private businesses ( 23 percent). This aligns with the distribution for all calls reported to NEMSIS. Fire departments transport a greater percentage of calls in urban areas, and government non-fire entities and private firms transport more in rural areas. EMT paramedics attend to over 85 percent of the calls in all areas. Most calls are staffed 
by paid staff. ${ }^{16}$ Over half the locations of the incidents are in the South region of the United States. About 81 percent of the calls are in urban areas. Over 73 percent of calls are during a weekday and about 13 percent of the calls occur during the morning rush hour and 19 percent occur during the evening rush hour.

Comparing the estimates between calls in treated and comparison zip codes, we see that, for the most part, the numbers are similar which is what we would expect if our matching process produced a comparison sample that was similar to the treated sample. This provides some evidence that we were successful in matching similar zip codes. However, there are still some notable differences between the treated and comparison groups. Fire department ambulances undertake a smaller percentage of calls in treated areas, while private, non-hospital ambulances make up a larger proportion of calls in treated areas. In addition, calls in treated areas are less likely to have volunteer staff in the ambulance. These remaining differences are one reason why we use the empirical methodology that we describe in the next section.

Another way to assess the success of our matching procedure is to compare our data to all calls in the NEMSIS data as well as to call times reported in the previous literature. On average over all years and calls, the mean transport time in our sample is 14.6 minutes. ${ }^{17}$ This is almost identical to the average transport time for all calls in NEMSIS in 2010-2015 which is 14.7 minutes. Mueller et al. (2016) report a median transport time of 11-12 minutes. In summarizing transport times from 20 states reported in 30 years of ambulance literature Pons et al. (2005), report transport times for urban and rural areas of 10.8 and 17.3 minutes, respectively. In Table 3 we report mean transport times for the year before and the year after a hospital closes for the treatment and comparison zip codes. These times are quite similar to the estimates from the full data sample and from the previous studies, providing additional evidence that our matched data are similar to other data on ambulance calls.

\section{Empirical Methodology}

\footnotetext{
${ }^{16}$ NEMSIS data has information on the type of call which indicates whether the call was basic or advanced life support. We chose not to use this information because over 40 percent of the data from this field are missing. When we run our analysis including this information the results are similar.

${ }^{17} \mathrm{We}$ focus on transport time - the time it takes to get a patient from the scene to the hospital— because that is what is reported in these previous studies.
} 
To estimate the impact of a hospital closure in a zip code on the length of time of ambulance calls, we use the following empirical model:

$$
Y_{t}=\beta_{0}+\beta_{1} \text { year }+\beta_{2} \text { hospitalclose }+\delta_{1} \text { year } \cdot \text { hospitalclose }+\beta_{3}^{\prime} X+\varepsilon \text {. }
$$

$Y_{t}$ includes four different outcome variables: the total time of the ambulance call (total response time) in period $t$; the time it takes the ambulance to arrive at the scene after receiving the call (time to scene) in period $t$; the time the ambulance spends at the scene (scene time) in period $t$; and transport time in period $t$, which is the time from the scene until arriving at the hospital. All of these variables are measured in minutes. Year is a dummy variable which equals zero if the ambulance run occurs in the year prior to the hospital closing and one in the year after the hospital closes. Hospitalclose is equal to one for all ambulance calls in zip codes with closures and is zero otherwise. $\boldsymbol{X}$ is a matrix of observable characteristics of the ambulance call. $\boldsymbol{X}$ includes patient age and gender, ownership type of the ambulance (fire department, hospitalbased, etc.), the highest level of medical staff available on the ambulance, whether the ambulance includes any volunteer staff and whether the incident took place on a weekday and if it was during morning or evening rush hour, as well as Census region.

$\delta_{1}$ is our estimate of the treatment effect of a hospital closing in a zip code and is our main coefficient of interest. It measures the difference in the change in the average ambulance run time between the year prior to the match year and the year after the match year between the treated and comparison zip codes:

$$
\widehat{\delta_{1}}=\left(\overline{Y_{\text {post }, \text { treated }}}-\overline{Y_{\text {pre,treated }}}\right)-\left(\overline{Y_{\text {post }, \text { comparison }}}-\overline{Y_{\text {pre,comparison }}}\right)
$$

This type of estimator is referred to as a difference-in-difference estimator (DD). There are several reasons for using this type of regression for estimating the treatment effect in this setting. First, it allows us to control for other characteristics of the call relative to simply calculating the difference in the change in average response time between treated and comparison zip codes. Second, the Hospitalclose variable controls for any remaining observable and unobservable differences between treated and comparison zip codes that are unrelated to the hospital closing and are not captured by changes in ambulance response times. Including the Year and Hospitalclose dummy variables means that identification of $\delta_{1}$ comes from changes within the treated and comparison groups and changes in the time of the ambulance run between the two years. 
When estimating the standard errors in our regression, we cluster on the hour of the day, the day of the week and the year when the run occurs as well as the urban variable. Ideally, we would like to cluster on zip code, but as stated above, NEMSIS strips this information off the data file before returning the file to us. There are 2016 unique day-hour clusters. Since clustering in this manner will capture possible dependence in the errors that are related to the time, day, year and location of the ambulance run, we believe this allows us to calculate reasonably accurate standard errors.

\section{Results}

\section{Mean Differences}

Table 3 presents the mean total response time (row 1), time to scene (row 2), scene time (row 3 ) and transport time to the hospital (row 4) for all calls in treated and comparison groups for the year before (Pre) and the year after (Post) hospital closure as well as the mean change in these times (Diff). ${ }^{18}$ We also report the change in the differences between the treated and control zip codes (Diff-in-Diff). This table shows that in the year prior to a hospital closing total response time is approximately three minutes longer in zip codes where a hospital closes relative to zip codes where no hospital closes. This overall difference in response time is the result of both a longer time to scene as well as a longer transport time. The time spent at the scene is similar in the two groups of zip codes.

When we look at the change in times in the year after the hospital closes we see that in the treated zip codes the total response time increased by a little over one minute, while in the comparison sample there is essentially no change in the total response time over the years. This results in an overall increase in total response times in the treated zip codes relative to the comparison zip codes of 1.15 minutes (column 7).

Our hypothesis is that, at least in the short run, any change in response times we see will be the result of an increase in transport time. Since it is unlikely that ambulance companies will have changed locations in the short-run, nor is there likely to be any change in where people live,

\footnotetext{
${ }^{18}$ We calculated the means for total response times for all observations to compare to the data with the total response times between 10 minutes and 120 minutes. We found the means and standard deviations are larger when we include the wider range of call times for treated and comparison groups illustrating the variability in the times. When we subtract times less than 10 minutes and greater than 120 minutes, the mean times drop by about one minute.
} 
we would not expect to see any change in the time it takes for an ambulance to arrive at the scene. We do not expect to see any change in the severity of the average patient's condition in the short run, so we do not expect to see any changes in scene time. There are a couple of reasons why our hypotheses could be wrong. First, if a hospital closing in an area results in an increase in the total transport time, then this could increase the probability that an ambulance is on a call and unavailable to transport a new patient, requiring that an ambulance from farther away come and transport the patient, or requiring a patient to wait until the ambulance completes the prior run. Both would lead to an increase in time to scene. In addition, if ambulance drivers know that it will take longer to transport a patient to the hospital, then they may try to arrive to the scene faster and once at the scene spend more time trying to stabilize a patient prior to transporting them (Wilde, 2013; Mueller et al., 2016). This could then lead to a decrease in time to scene and/or an increase in scene time. Finally, patients may respond to the increase in the time it takes to get to a hospital by choosing some alternative means of transportation, particularly for less severe conditions (Buchmueller et al., 2006; Moskatel et al., 2019). This sorting would mean that ambulances are dealing with more severe conditions on the typical run, which could also lead to an increase in scene time.

Looking at the results in Table 3 we see that there is essentially no relative change in the time an ambulance takes to get to the scene, nor any change in the relative time an ambulance spends at the scene. The increase in total response time is primarily due to a relative increase in transport time - the time it takes to get the patient from the scene - of 1.86 minutes. At least in the short run we find no evidence suggesting that there is an increase in the probability an ambulance is unavailable to transport a patient, nor do ambulances appear to spend more time at the scene due to an increase in the severity of patients' conditions, or in an attempt to further stabilize the patients prior to transporting them. The primary impact is on the transport time - the time a patient spends in the ambulance being transported to the hospital.

\section{Regression Results}

Difference-in-differences regressions of total response time, time to scene, scene time and transport time based on equation (1) are reported in Table 4. Clustered standard errors are in parentheses. In columns (1), (3), (5), and (7) we report regression results without any additional controls, which should exactly replicate the information in Table 3. In columns (2), (4), (6), and (8) we present results controlling for the set of variables discussed in Section IV. 
In column (1), the coefficient on the year*hospitalclose interaction shows that a hospital closure in a treated zip code is associated with a relative increase in total response time of 1.15 minutes-identical to the results in Table 3. In column (2) we see that including our full set of controls increases the relative time to 1.79 minutes. Comparing the estimate for total response time reported in column (2) with those reported in columns (4), (6) and (8) we continue to see that the relative increase in total response time is almost exclusively the result of an increase in transport time. At least in the short run, we continue to find no evidence that the hospital closure leads to a change in the behavior of ambulance companies or patients that would lead to an increase in the time it takes to get to the scene or the time an ambulance spends at the scene.

While we do find a positive and significant increase in both total response time and transport time, it is worth mentioning that given that we have over 13.7 million observations, simply finding a statistically significant result is not sufficient. We also need to consider whether we find a meaningful impact. Using this criterion, the increases we see do not appear to be particularly meaningful. In Table 4 in column (2) if we sum the constant with the coefficient on the Hospitalclose variable this provides us with an estimate of the average total response times in zip codes where a hospital closed in the year prior to closing of 33.87 minutes. Dividing the increase in total transport time of 1.79 minutes by 33.87 minutes shows that this change represents a 5.3 percent increase in total response time ${ }^{19}$ However, focusing on transport time (column 8) we do find that once we control for other characteristics, patients in zip codes where hospitals close experience a 2.19 minute increase in transport time, which represents a fifteen percent increase relative to the year prior to the hospital closing.

In considering the impact of a hospital closing, one area that receives a lot of attention in both the academic literature and the popular press are rural communities. The concern is that, because hospitals are located further away from residents in rural as compared to urban areas, the impact of a hospital closing could be larger since it will force patients to travel farther to get to the next closest hospital. Of course, these concerns do not take into account the costs of operating a hospital in an area with falling demand for hospital services, nor do they take into account the possibility that the quality of care provided in a failing hospital could be well below

\footnotetext{
${ }^{19}$ In this comparison we are assuming that had the hospital not closed in a zip code, ambulances in the zip code would have experienced the same change in total response times as ambulances in zip codes where a hospital did not close. Throughout the paper we will use this same metric when computing the percentage change in times in zip codes where a hospital closed.
} 
the quality provided in the next closest hospital, which could mean that a patient receives much better treatment at the next closest hospital (Nicholl et al., 2007; Buchmueller et al., 2006). ${ }^{20}$

In order to provide evidence on this issue, we estimate our regressions separately for hospital closures in rural and urban zip codes. ${ }^{21}$ The results for hospital closures occurring in rural zip codes are presented in Table 5 while the results for hospital closures in urban zip codes are presented in Table 6. The results in Table 5 show that a hospital closure in a rural area is associated with over a fifteen-minute relative increase in total response time. This estimate is both statistically significant and meaningful as it represents an almost fifty percent increase in total response time relative to the year prior to the closure. Looking at the results for transport time, we continue to see that most of this increase is the result of a significant increase in transport time. However, we also see that relative scene time increased by 1.84 minutes for rural zip codes where a hospital closed, which represents an eighteen percent increase over the scene time in the prior year. This offers some support for the Mueller et al. (2016) hypothesis that ambulance drivers spend more time at the scene providing additional treatment in anticipation of a longer time traveling to the hospital. We continue to see no relative increase in the time to scene, again suggesting that ambulance drivers do not change their behavior in response to a hospital closing in a rural area, at least in the short run.

In contrast to the results for rural areas, the results in Table 6 for urban zip codes show that a hospital closure is associated with a decline in total response times in urban zip codes where a hospital closed, although the estimate is small in magnitude. We also see small negative coefficients in the Time to Scene and Scene Time regressions and insignificant coefficients in the Transport Time regressions. Based on these results it appears that a hospital closing in an urban zip code has almost no impact on patients' ambulance call time in the zip code.

Because Medicare-eligible people are proportionally the biggest users of ambulance services, we also examine the impact of a hospital closure on this group by restricting our estimation to only include data where the patient is sixty-five years old or older. The results are reported in

\footnotetext{
${ }^{20}$ Unfortunately, our data do not allow us to address these issues either.

${ }^{21}$ In our propensity score matching procedure, we do include a dummy for the population density of the zip code as a measure of the ruralness of a zip code in the logit model estimating the probability that a zip code contains a hospital that closes. However, we do not force rural zip codes to be matched exclusively to other rural zip codes, or urban zip codes only match with urban zip codes. So, it is possible for the comparison group of rural zip codes to contain urban zip codes and vice-versa.
} 
Table 7 for all zip codes, and Tables 8 and 9 for rural and urban zip codes, respectively. The estimates reported in Table 7 provide evidence suggesting that a hospital closure may have a larger impact on older patients relative to patients younger than sixty-five years old. In column (2) the estimate shows that over all zip codes in our data, a hospital closure is associated with a greater than four-minute relative increase in total response time with most of the increased time coming from a relative increase in transport time. Relative to the prior year, this represents a ten percent increase for total response time and a twenty-two percent increase in transport time. Tables 8 and 9 , show that the impact of a hospital closure for this population is also substantially larger in rural areas relative to urban areas with the largest changes occurring in the transport time. For the rural areas additional transport time is 15.6 minutes, sixty-one percent increase over the prior year.

\section{Robustness Checks}

As we discussed earlier, one concern with our data is that there is an increase in the number of states and the number of regions within a state that report data to NEMIS overtime. In order to see if this increase in the number of reporters in a year influences our results, we estimate our regression models separately by year of the hospital closure. We do this for all zip codes, as well as separately for rural and urban zip codes. In this analysis we focus exclusively on total response time as our dependent variable. The results for all zip codes are presented in Appendix Table A1, the results for rural zip codes are presented in Appendix Table A2 and the results for urban zip codes are presented in Appendix Table A3. In all three tables the coefficient showing the relative impact of a hospital closure tends to vary across the years of the data. This is likely because in any given year we have relatively few zip codes where a hospital closes. However, overall the results continue to show that the impacts are larger in rural areas and smaller in urban areas (with the exception of 2011). It also appears that the largest estimate of the impacts of a hospital closing is found for match year 2011. Based on this finding we re-estimate our main regression equations dropping data from 2011 and find similar results. ${ }^{22}$ Other than this, we do not see any systematic pattern in the variation of the coefficients across years, providing some evidence that changes in the sample over the years are not biasing our results.

${ }^{22}$ Results available from the authors upon request. 
Another factor that could affect our results is the implementation of the Affordable Care Act (ACA) in 2014. Given the results from Courtemanche et al. (2019) showing that the implementation of the ACA leads to an increase in the number of ambulance calls and an increase in the time it took an ambulance to get to the scene of a motor vehicle accident, we reestimated all of our basic regressions including a dummy variable for the year after the implementation of the ACA (2014 and 2015). Including this variable had no impact on our results. ${ }^{23}$ We also do not see any differences in the 2014 estimates relative to the other years in Tables A1-A3, which again suggests that the implementation of the ACA is not impacting our results.

One possibility we are concerned about is whether ambulance operators anticipate that a hospital is going to close and start transporting patients to the next closest hospital prior to the hospital closing. One reason this might occur is if the quality of care a hospital provides is a signal of the future closing of a hospital and the ambulance operator responds to this decline in care by choosing to transport patients to a different hospital. In order to examine whether this potential change in behavior by ambulance owners prior to the hospital closing is affecting our results we perform a falsification test by seeing whether we can identify an effect prior to the date the hospital closes. To perform this test, we code the hospital as having closed two years earlier than the actual closing date and re-estimated our regressions. For example, for treated and comparison zip codes associated with a hospital closure in 2014, we code the closure year as 2012 and then examine the change in ambulance response times between 2011 and 2013 . We select two years earlier to avoid including data on ambulance response times in the year in which the hospital actually closes. Because the NEMSIS data are only available back to 2010, we can run this test for only two years, 2013 and 2014 using the data from 2010 through 2012. We report the results from this test for all zip codes in Appendix Table A4, for rural zip codes in Appendix Table A5 and for urban zip codes in Appendix Table A6.

The coefficient estimates reported in Appendix Table A4 suggest that ambulance operators are adjusting their behavior prior to a hospital closing. In this table we see that relative total response times in zip codes with future hospital closures increased by 6.3 minutes in the year prior to the hospital closing, and that most of this change is due to the relative increase in

\footnotetext{
${ }^{23}$ Results available from the authors upon request.
} 
transport time. Looking at the results in Appendix Table A5 we see no significant change in any of the times in the years prior to the hospital closing in rural zip codes. There is no evidence that ambulance operators change their behavior in rural areas in reaction to the future closing of a hospital. In contrast, in Appendix Table A6 we see that in urban areas response times experience a relative increase of 10.6 minutes in regressions where we include all of our controls (column 2) and that this change results from a relative increase in the time an ambulance spends at the scene of 4.0 minutes, and an increase transport time of 5.5 minutes. If we combine the estimate of 10.6 from the Total Response Time regression in Appendix Table A6 column (2) with the estimate of -0.79 from the Total Response Time regression in Table 6 column (2), we have an estimated overall impact of a relative increase in total response time in urban areas of 9.8 minutes. This is certainly much larger than the estimate in Table 6 but remains smaller than the estimated relative increase in total response time in rural areas from Table 5. The results from this falsification test provide evidence that hospital closures in urban areas do result in an increase in ambulance response times, but that the increase is in the year prior to the hospital closing is still smaller than the increase in rural areas.

Another issue we want to examine further is whether changes in individuals' behavior could account for some of the changes we see. As mentioned in the literature review, one possibility is that if patients know their local hospital has closed and they will face a longer ride in an ambulance they may seek alternative ways to get to the hospital, may be more likely to wait and see their primary care provider, or may only call an ambulance for more severe emergencies. Any of these changes could results in ambulances having to deal with more severe cases which take more time to treat which could lead to longer total responses times. ${ }^{24} \mathrm{We}$ start by comparing changes in the number of ambulance calls in our treated zip codes with changes in the number of ambulance calls in the comparison zip codes. We find that the number of calls increases in both treated and comparison zip codes, with the percentages change being larger in treated zip codes.

We also looked for any systematic changes in the reasons why individuals are calling an ambulance. The NEMSIS data provide the chief complaint reported to the dispatcher. The top four complaints by percent of all calls are Sick Person (18\%), Breathing Problem (12\%), Fall Victim (10\%) and Chest Pain (9\%). We look at whether there is any differential change in the

\footnotetext{
${ }^{24}$ We see some evidence of this in Table 5 for rural areas where there is a significant relative increase in scene time in zip codes where a hospital has closed.
} 
distribution of complaints for patients in treated and comparison zip codes. We find no evidence of any differential change in the distribution of complaints in all areas and when we look separately at rural and urban zip codes. It does not appear that people are calling an ambulance relatively less often or for different reasons immediately after a hospital closes in a zip code. ${ }^{25}$

\section{Conclusions}

Over the years, stakeholders such as the Medicare program, the National Rural Health Association and the American Hospital Association, have prioritized maintaining local access to emergency services especially in rural communities. For example, in 1997, the Medicare Rural Hospital Flexibility grant was established to, among other things, assist in maintaining emergency services in rural areas. ${ }^{26}$ In the 2017 annual report of the Medicare Payment Advisory Commission, the commissioners stressed the need to find more efficient and financially stable ways to deliver emergency services in rural communities. The National Advisory Committee on Rural Health and Human Services (2016) in a policy brief emphasized the need for ambulance services when discussing preserving access to emergency care.

Our study contributes to the conversation about emergency care by focusing on ambulance service. It is the only study we know of that measures changes in ambulance call times when there has been a hospital closure - a major shock to health care in the community. Taking all the results together, we conclude that a hospital closure in a rural area has a much larger impact on the total time it takes an ambulance to transport a patient to the hospital and the total time in an ambulance in rural areas is more impacted by hospital closures than in urban areas. Compared to zip codes with a similar probability of having a hospital closure, patients in the rural treated zip codes experience a sixteen minute increase in total response time, which represents a forty-six percent increase, and experience on average fourteen minutes or almost a doubling in the time spent in the ambulance getting to the hospital. We also find evidence that older patientsMedicare-eligible patients - experience an even larger increase in total response time in rural area after a hospital closes of eighteen minutes. The empirical methodology we employ allows us to make a plausible causal argument that in the short run, within one year of closure, rural and elderly patients are particularly affected by hospital closures.

\footnotetext{
${ }^{25}$ Both of these results are available from the authors upon request.

${ }^{26}$ Information about the Medicare Rural Hospital Flexibility program can be found at www.ruralcenter.org/tasc.
} 
When a hospital and ED closes, it is important to think about who is most likely affected by the closure and how the changes impact their access to care. Previous studies found both rural and urban communities where hospitals closed tended to have a higher percentage of elderly and poor residents in addition to higher unemployment rates and a higher percentage of blacks and Hispanics patients (Kaufman et al., 2016; Thomas et al., 2015). More than half the hospitals in the country are in rural areas and are the primary source of emergency medical services in these communities. When asked to rank attributes of rural health care facilities in a recent study, rural residents strongly valued access to emergency services through EDs in their communities (Allen, Davis, $\mathrm{Hu}, \&$ Owusu-Amankwah, 2015; Buchmueller et al., 2005).

Our analysis has some important limitations. We only consider zip codes where a hospital closed and selected comparison zip codes with hospitals. We do not observe how patients in neighboring zip codes are affected. We also only focus on short-run effects. In the long run the effect may change because the ambulance service may change locations to optimize service, or residents may move due to job loss at the hospital or to be closer to ED services.

Since we do not have information about patient health outcomes, we cannot comment directly on the important question of how changes in total response time and transport time impact patient outcomes. However, based on our results and earlier studies in urban areas it seems that there are likely only minimal impacts on patient health resulting from changes in ambulance service where a hospital closes, because we see only small changes in the time patients spend in an ambulance after a hospital closes in an urban area. For rural areas, we do not expect a change in health outcomes due to the time to scene and scene time as these times are unchanged from pre to post year of the hospital closure. The only health change due to the hospital closure would be the added transport time to the hospital ED. Unfortunately, there is very little literature addressing this component of the ambulance trip and its effect on health outcomes and the literature that does exist tends to only examine patients with certain conditions and finds conflicting results, with some studies reporting increases in transport time leading to an increase in mortality, while others find no impact on mortality from increased transport time (Jena et al., 2017; Newgard et al., 2010; Nicholl et al., 2007). In the end, our study does point out the importance of tying data from the ambulance transport with patient outcome data in order to assess the full cost of a hospital closure, particularly in rural areas. 


\section{References}

Allen, J. E., Davis, A. F., Hu, W., \& Owusu-Amankwah, E. (2015). Residents' Willingness-toPay for Attributes of Rural Health Care Facilities. The Journal of Rural Health, 31(1), 718.

Blackwell, T. H., Kline, J. A., Willis, J. J., \& Hicks, G. M. (2009). Lack of Association Between Prehospital Response Times and Patient Outcomes. Prehospital Emergency Care, 13(4), 444-450.

Buchmueller, T. C., Jacobson, M., \& Wold, C. (2006). How far to the hospital?: The effect of hospital closures on access to care. Journal of Health Economics, 25(4), 740-761.

Courtemanche, C., A. Friedson, A. P. Koller \& D. I. Rees. (2019) The affordable care act and ambulance response times. Journal of Health Economics, 67.

David, G., \& Brachet, T. (2011). On the determinants of organizational forgetting. American Economic Journal: Microeconomics, 3(3), 100-123.

Doyle, J. J., Graves, J. A., Gruber, J., \& Kleiner, S. A. (2015). Measuring Returns to Hospital Care: Evidence from Ambulance Referral Patterns. Journal of Political Economy, 123(1), 170-214.

Goldstein, A. (2017, April 11). In the Tennessee Delta, a poor community loses its hospital and sense of security. Washington Post.

Heinrich, C. J., Maffioli, A., \& Vázquez, G. (2010). A Primer for Applying Propensity-Score Matching, Impact-Evaluation Guidelines Technical Notes (No. IDB-TN-161). Washington DC.

Heinrich, C. J., Mueser, P. R., Troske, K. R., Jeon, K.-S., \& Kahvecioglu, D. C. (2013). Do public employment and training programs work? IZA Journal of Labor economics, 2(1), 6.

Hsia, R. Y., Kanzaria, H. K., Srebotnjak, T., Maselli, J., McCulloch, C., \& Auerbach, A. D. (2012). Is Emergency Department Closure Resulting in Increased Distance to the Nearest Emergency Department Associated with Increased Inpatient Mortality? Annals of emergency medicine, 60(6), 707-715.e704.

Jena, A. B., Mann, N. C., Wedlund, L. N., \& Olenski, A. (2017). Delays in Emergency Care and Mortality during Major U.S. Marathons. New England Journal of Medicine, 376(15), 1441-1450.

Kaufman, B. G., Thomas, S. R., Randolph, R. K., Perry, J. R., Thompson, K. W., Holmes, G. M., \& Pink, G. H. (2016). The Rising Rate of Rural Hospital Closures. The Journal of Rural Health, 32(1), 35-43.

Ko, M., Needleman, J., Derose, K. P., Laugesen, M. J., \& Ponce, N. A. (2014). Residential segregation and the survival of US urban public hospitals. Medical Care Research and Review, 71(3), 243-260.

Lee, D. C., Carr, B. G., Smith, T. E., Tran, V. C., Polsky, D., \& Branas, C. C. (2015). The Impact of Hospital Closures and Hospital and Population Characteristics on Increasing Emergency Department Volume: A Geographic Analysis. Population Health Management, 18(6), 459-466.

Mann, N. C., Kane, L., Dai, M., \& Jacobson, K. (2015). Description of the 2012 NEMSIS Public-Release Research Dataset. Prehospital Emergency Care, 19(2), 232-240.

McCoy, C. E., Menchine, M., Sampson, S., Anderson, C., \& Kahn, C. (2013). Emergency Medical Services Out-of-Hospital Scene and Transport Times and Their Association 
With Mortality in Trauma Patients Presenting to an Urban Level I Trauma Center. Annals of Emergency Medicine, 61(2), 167-174.

Medicare Payment Advisory Commission. (2017). Report to Congress: Medicare Payment Policy, Hospital inpatient and outpatient services. Retrieved from http://www.medpac.gov/docs/default-source/reports/mar17 medpac ch3.pdf?sfvrsn=0.

Moskatel, L., \& Slusky, D. (2019). Did UberX reduce ambulance volume? Health Economics, 28(7), 817-829.

Mueller, L. R., Donnelly, J. P., Jacobson, K. E., Carlson, J. N., Mann, N. C., \& Wang, H. E. (2016). National Characteristics of Emergency Medical Services in Frontier and Remote Areas. Prehosp Emerg Care, 20(2), 191-199.

Mueser, P. R., Troske, K. R., \& Gorislavsky, A. (2007). Using state administrative data to measure program performance. The Review of Economics and Statistics, 89(4), 761-783.

National Advisory Committee on Rural Health and Human Services. (2016). Alternative models to preserving access to emergency care. Retrieved from https://www.hrsa.gov/advisorycommittees/rural/publications/alternatemodel.pdf

National Fire Protection Association. (2016). NFPA 1710, Standard for the Organization and Deployment of Fire Suppression Operations, Emergency Medical Operations, and Special Operations to the Public by Career Fire Departments. Retrieved from https://www.nfpa.org/codes-and-standards/all-codes-and-standards/list-of-codes-andstandards/detail? code $=1710$

NEMSIS. (2016). National EMS Database NEMSIS Research Data Set v. 2.2.1, 2015 User Manual. Retrieved from: https://nemsis.org/media/reportingTools/documents/NEMSISRDS2212015UserManual_ 000.pdf

Newgard, C. D., Schmicker, R. H., Hedges, J. R., Trickett, J. P., Davis, D. P., Bulger, E. M., . . . Gubler, K. D. (2010). Emergency medical services intervals and survival in trauma: assessment of the "golden hour" in a North American prospective cohort. Annals of emergency medicine, 55(3), 235-246. e234.

Nichol, G., Detsky, A. S., Stiell, I. G., O'rourke, K., Wells, G., \& Laupacis, A. (1996). Effectiveness of emergency medical services for victims of out-of-hospital cardiac arrest: a metaanalysis. Annals of emergency medicine, 27(6), 700-710.

Nicholl, J., West, J., Goodacre, S., \& Turner, J. (2007). The relationship between distance to hospital and patient mortality in emergencies: an observational study. Emergency Medicine Journal : EMJ, 24(9), 665-668. doi:10.1136/emj.2007.047654

Pell J.P., J.M. Sirel, A.K. Marsden,I. Ford \& S.M. Cobbe. (2001). Effect of reducing ambulance response times on deaths from out of hospital cardiac arrest: cohort study. $B M J$, 322:1385.

Pons, P. T., Haukoos, J. S., Bludworth, W., Cribley, T., Pons, K. A., \& Markovchick, V. J. (2005). Paramedic response time: does it affect patient survival? Academic Emergency Medicine, 12(7), 594-600.

Pons, P. T., \& Markovchick, V. J. (2002). Eight minutes or less: does the ambulance response time guideline impact trauma patient outcome? The Journal of emergency medicine, 23(1), 43-48.

Samuels, S., Cunningham, J. P., \& Choi, C. (1991). The impact of hospital closures on travel time to hospitals. Inquiry, 194-199. 
Sanghavi, P., Jena, A. B., Newhouse, J. P., \& Zaslavsky, A. M. (2015). Outcomes of basic versus advanced life support for out-of-hospital medical emergencies. Annals of internal medicine, 163(9), 681-690.

Sun, B. C., Mohanty, S. A., Weiss, R., Tadeo, R., Hasbrouck, M., Koenig, W. Meyer, C, Asch, S. (2006). Effects of hospital closures and hospital characteristics on emergency department ambulance diversion, Los Angeles County, 1998 to 2004. Annals of Emergency Medicine, 47(4), 309-316.

The Darmouth Institute for Health Policy and Clinical Practice. (2017). The Dartmouth Atlas of Health Care. Retrieved from http://www.dartmouthatlas.org/data/region/

The Henry J. Kaiser Family Foundation. (2012). Medicaid Benefits: Ambulance Services. Retrieved from https://www.kff.org/medicaid/state-indicator/ambulance-services.

Thomas, S. R., Kaufman, B. G., Randolph, R., Thompson, K., Perry, J. R., \& Pink, G. H. (2015). A Comparison of closed rural hospitals and perceived impact. Findings Brief. NC Rural Health Research Program.

U.S. Census Bureau. (2013) American Community Survey 2009-2013. Retrieved at https://factfinder.census.gov/faces/nav/jsf/pages/searchresults.xhtml?refresh=t.

U.S. Centers for Medicare and Medicaid Services. (2010-2016a). Hospital Compare. Retrieved from https:/www.medicare.gov/hospitalcompare/About/What-Is-HOS.html

U.S. Centers for Medicare and Medicaid Services. (2010-2016b, February 22, 2017). Provider of Services Current Files. Retrieved from https://www.cms.gov/Research-Statistics-Dataand-Systems/Downloadable-Public-Use-Files/Provider-of-Services/index.html.

U.S. Centers for Medicare and Medicaid Services. (2016). Medicare Benefit Policy Manual, Chapter 10 - Ambulance Services. Retrieved from https://www.cms.gov/Regulations-andGuidance/Guidance/Manuals/downloads/bp102c10.pdf.

U.S. Government Accountability Office. (2006). Hospital Quality Data: CMS Needs More Rigorous Methods to Ensure Reliability of Publicly Released Data. Washington, DC: U.S. Government Accountability Office.

Wilde, E. T. (2013). Do Emergency Medical System Response Times Matter for Health Outcomes? Health Economics, 22(7), 790-806.

Williams, D., Hadley, J., \& Pettengill, J. (1992). Profits, community role, and hospital closure: An urban and rural analysis. Medical Care, 174-187. 
Figure 1: Hospital Closures, 2011-2014

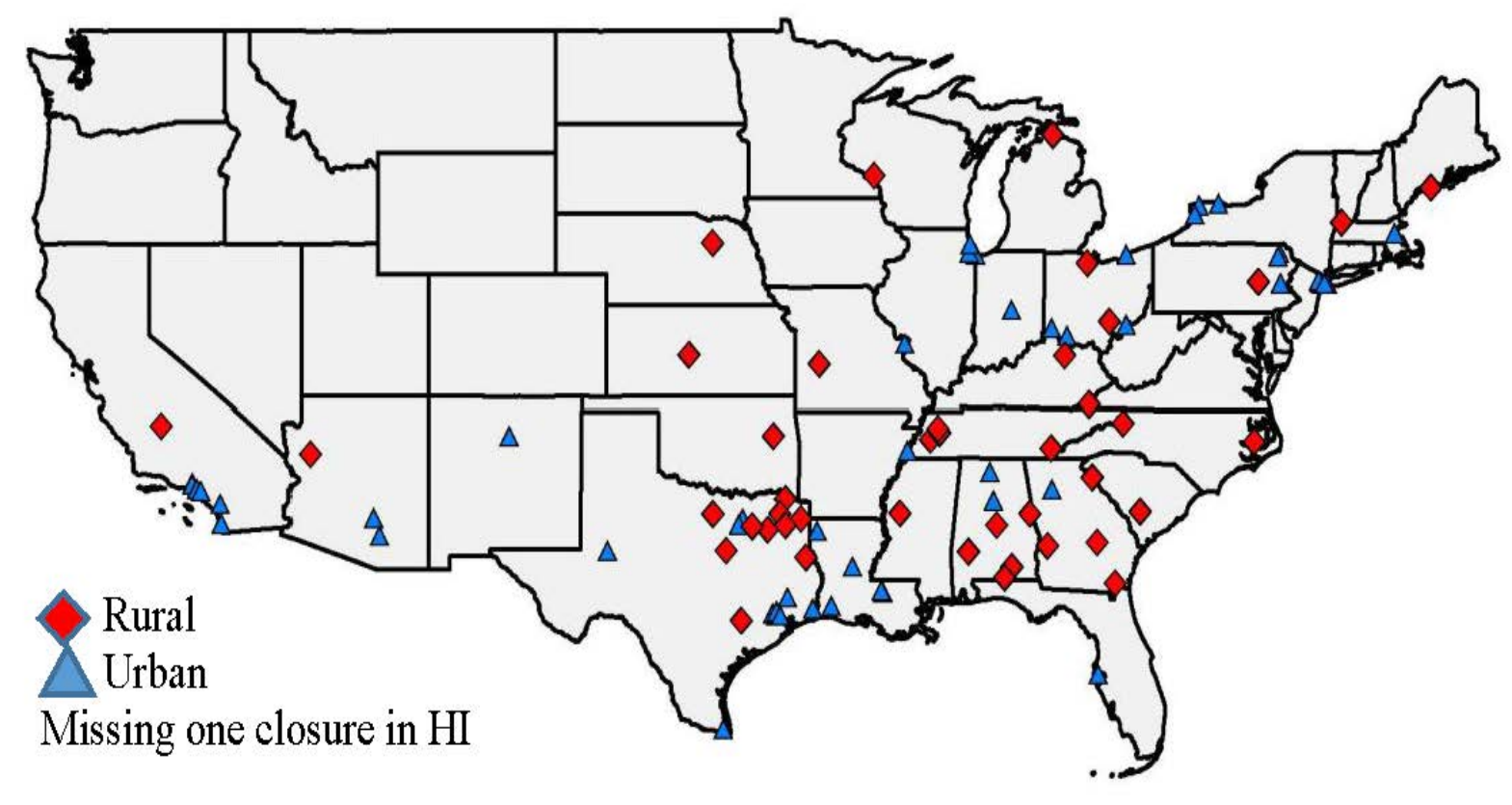


Table 1: Characteristics of Selected Hospital Closures and All Closures, 2011-2014

\section{Closures selected} for study

\begin{tabular}{|c|c|c|}
\hline Number of hospitals (all years) & 51 & 91 \\
\hline Urban $(\%)$ & 44.0 & 52.7 \\
\hline Rural (\%) & 56.0 & 47.3 \\
\hline $\begin{array}{l}\text { Mean number of beds } \\
\quad \text { (standard deviation) }\end{array}$ & $\begin{array}{c}123.7 \\
(181.2)\end{array}$ & $\begin{array}{c}109.9 \\
(147.3)\end{array}$ \\
\hline \multicolumn{3}{|l|}{ Census Region $(\%)$} \\
\hline Northeast & 22.0 & 14.3 \\
\hline Midwest & 14.0 & 16.5 \\
\hline South & 52.0 & 56.0 \\
\hline West & 12.0 & 12.2 \\
\hline
\end{tabular}


Table 2: Mean Patient, Ambulance Service and Incident Characteristics, across ambulance calls for the matched sample

\begin{tabular}{|c|c|c|c|c|c|}
\hline Variable & Total & Treated & Comparison & Urban & Rural \\
\hline \multicolumn{6}{|l|}{ Patient characteristics } \\
\hline Female $(\%)$ & 54.71 & 53.00 & 54.72 & 54.51 & 55.55 \\
\hline Age (mean in years) & 55.94 & 51.97 & 55.96 & 55.32 & 58.62 \\
\hline \multicolumn{6}{|l|}{ Ambulance service characteristics } \\
\hline \multicolumn{6}{|l|}{ Ownership type (\%) } \\
\hline Community Nonprofit & 12.68 & 20.58 & 12.64 & 12.72 & 12.51 \\
\hline Fire Department & 26.08 & 19.50 & 26.11 & 27.94 & 18.16 \\
\hline Government Non fire & 23.49 & 14.74 & 23.53 & 23.51 & 23.41 \\
\hline Hospital & 14.55 & 11.99 & 14.56 & 12.77 & 22.14 \\
\hline Private Non-Hospital & 23.20 & 33.19 & 23.15 & 23.06 & 23.78 \\
\hline \multicolumn{6}{|l|}{ Staff medical status (\%) } \\
\hline EMT Basic & 4.36 & 1.08 & 4.37 & 4.19 & 5.06 \\
\hline EMT Intermediate & 1.47 & 2.30 & 1.46 & 1.01 & 3.42 \\
\hline EMT Paramedic & 85.14 & 84.28 & 85.14 & 85.27 & 84.57 \\
\hline Other medical & 9.04 & 12.34 & 9.02 & 9.52 & 6.94 \\
\hline \multicolumn{6}{|l|}{ Staff volunteer/non-volunteer(\%) } \\
\hline Mixed & 18.54 & 3.78 & 18.54 & 17.76 & 21.49 \\
\hline Non-volunteer & 78.98 & 92.09 & 78.98 & 80.37 & 73.38 \\
\hline Volunteer & 2.49 & 4.13 & 2.48 & 1.87 & 5.13 \\
\hline \multicolumn{6}{|l|}{ Incident characteristics } \\
\hline \multicolumn{6}{|l|}{ Census Region $(\%)$} \\
\hline Midwest & 21.70 & 14.22 & 21.73 & 18.85 & 33.84 \\
\hline Northeast & 16.16 & 27.27 & 16.11 & 18.85 & 4.69 \\
\hline South & 53.34 & 42.82 & 53.39 & 53.76 & 51.55 \\
\hline West & 8.81 & 15.70 & 8.77 & 8.55 & 9.92 \\
\hline Urban (\%) & 81.01 & 82.40 & 81.00 & na & na \\
\hline \multicolumn{6}{|l|}{ Time of day (\%) } \\
\hline Weekday & 73.05 & 73.19 & 73.05 & 73.18 & 72.49 \\
\hline Weekend & 26.95 & 26.81 & 26.95 & 26.82 & 27.51 \\
\hline Morning rush hour & 12.57 & 12.09 & 12.57 & 12.37 & 13.41 \\
\hline Evening rush hour & 19.48 & 19.56 & 19.48 & 19.57 & 19.08 \\
\hline Number of observations & $13,779,096$ & 62,163 & $13,716,933$ & $11,161,907$ & $2,617,189$ \\
\hline
\end{tabular}


Table 3: Mean Ambulance Call Times by Group and Pre and Post Match Year, minutes

\begin{tabular}{|c|c|c|c|c|c|c|c|}
\hline & \multicolumn{3}{|c|}{ Treated } & \multicolumn{3}{|c|}{ Comparison } & \multirow[b]{2}{*}{$\begin{array}{c}\text { Diff-in-Diff } \\
(7)\end{array}$} \\
\hline & $\begin{array}{l}\text { Pre } \\
(1)\end{array}$ & $\begin{array}{l}\text { Post } \\
(2)\end{array}$ & $\begin{array}{l}\text { Diff } \\
(3)\end{array}$ & $\begin{array}{l}\text { Pre } \\
(4)\end{array}$ & $\begin{array}{l}\text { Post } \\
\text { (5) }\end{array}$ & $\begin{array}{c}\text { Diff } \\
(6)\end{array}$ & \\
\hline $\begin{array}{l}\text { Total } \\
\text { Response } \\
\text { Time }\end{array}$ & $\begin{array}{l}37.43 \\
(17.5)\end{array}$ & $\begin{array}{l}38.62 \\
(17.1)\end{array}$ & $\begin{array}{l}1.18^{*} \\
(0.144)\end{array}$ & $\begin{array}{l}33.99 \\
(16.6)\end{array}$ & $\begin{array}{l}34.02 \\
(16.4)\end{array}$ & $\begin{array}{c}0.03 * \\
(0.009)\end{array}$ & $\begin{array}{c}1.15^{*} \\
(0.145)\end{array}$ \\
\hline $\begin{array}{l}\text { Time to } \\
\text { Scene }\end{array}$ & $\begin{array}{l}8.00 \\
(6.1) \\
\end{array}$ & $\begin{array}{l}7.41 \\
(5.0) \\
\end{array}$ & $\begin{array}{l}-0.59^{*} \\
(0.046)\end{array}$ & $\begin{array}{l}7.60 \\
(5.6) \\
\end{array}$ & $\begin{array}{l}7.63 \\
(5.5) \\
\end{array}$ & $\begin{array}{l}-0.03^{*} \\
(0.003) \\
\end{array}$ & $\begin{array}{l}-0.62 * \\
(0.048) \\
\end{array}$ \\
\hline Scene Time & $\begin{array}{l}15.95 \\
(8.6)\end{array}$ & $\begin{array}{l}15.93 \\
(9.5)\end{array}$ & $\begin{array}{l}-0.02 \\
(0.077)\end{array}$ & $\begin{array}{l}15.18 \\
(8.0)\end{array}$ & $\begin{array}{l}15.25 \\
(8.1)\end{array}$ & $\begin{array}{l}-0.06^{*} \\
(0.004)\end{array}$ & $\begin{array}{c}-0.08 \\
(0.075)\end{array}$ \\
\hline $\begin{array}{l}\text { Transport } \\
\text { Time }\end{array}$ & $\begin{array}{l}13.48 \\
(12.4)\end{array}$ & $\begin{array}{l}15.27 \\
(12.5)\end{array}$ & $\begin{array}{l}1.79^{*} \\
(0.104)\end{array}$ & $\begin{array}{l}11.21 \\
(11.6)\end{array}$ & $\begin{array}{l}11.14 \\
(11.3)\end{array}$ & $\begin{array}{c}0.07^{*} \\
(0.006)\end{array}$ & $\begin{array}{c}1.86^{*} \\
(0.104)\end{array}$ \\
\hline $\begin{array}{l}\text { Number of } \\
\text { Observations }\end{array}$ & 22,313 & 39,850 & & $6,125,989$ & $7,590,944$ & & \\
\hline
\end{tabular}

Note: Mean and (standard deviation) shown for columns 1, 2, 4 and 5. Standard errors shown in columns 3, 6 and 7 with “*” indicating $(\mathrm{P}<.01)$. The data include 911 transport by EMS to hospital, all ages. Observations are deleted if total response time (time to scene + scene time + transport time) $<10$ and >120 minutes and time to scene, scene time, transport time and total call time are missing.

Table 4: Total Response Time, Time to Scene, Scene Time and Transport Time for All Ambulance Calls $(\mathrm{N}=13,779,096)$

\begin{tabular}{|c|c|c|c|c|c|c|c|c|}
\hline \multirow[b]{2}{*}{$\begin{array}{l}\text { Independent } \\
\text { variables }\end{array}$} & \multicolumn{2}{|c|}{$\begin{array}{c}\text { Total Response } \\
\text { Time }\end{array}$} & \multicolumn{2}{|c|}{ Time to Scene } & \multicolumn{2}{|c|}{ Scene Time } & \multicolumn{2}{|c|}{ Transport Time } \\
\hline & (1) & (2) & (3) & (4) & (5) & (6) & (7) & (8) \\
\hline Constant & $\begin{array}{c}33.99 * \\
(0.03)\end{array}$ & $\begin{array}{c}30.78^{*} \\
(0.08)\end{array}$ & $\begin{array}{l}7.60 * \\
(0.01)\end{array}$ & $\begin{array}{l}7.31 * \\
(0.03)\end{array}$ & $\begin{array}{c}15.18^{*} \\
(0.01)\end{array}$ & $\begin{array}{l}9.42 * \\
(0.04)\end{array}$ & $\begin{array}{l}11.21^{*} \\
(0.02)\end{array}$ & $\begin{array}{c}14.05^{*} \\
(0.07)\end{array}$ \\
\hline $\begin{array}{l}\text { year*hospital } \\
\text { close }\end{array}$ & $1.15^{*}$ & $1.79 *$ & $-0.62 *$ & $-0.40^{*}$ & -0.08 & 0.01 & $1.86^{*}$ & $2.19 *$ \\
\hline & $(0.34)$ & $(0.29)$ & $(0.07)$ & $(0.07)$ & $(0.14)$ & $(0.13)$ & $(0.23)$ & $(0.20)$ \\
\hline year & $\begin{array}{c}0.03 \\
(0.03)\end{array}$ & $\begin{array}{l}0.28 * \\
(0.02)\end{array}$ & $\begin{array}{l}0.03 * \\
(0.01)\end{array}$ & $\begin{array}{l}0.10^{*} \\
(0.01)\end{array}$ & $\begin{array}{l}0.06^{*} \\
(0.01)\end{array}$ & $\begin{array}{l}0.11 * \\
(0.01)\end{array}$ & $\begin{array}{l}-0.07 \\
(0.03)\end{array}$ & $\begin{array}{l}0.07 * \\
(0.02)\end{array}$ \\
\hline hospital close & $\begin{array}{l}3.44^{*} \\
(0.19)\end{array}$ & $\begin{array}{l}3.09 * \\
(0.17)\end{array}$ & $\begin{array}{l}0.40 * \\
(0.06)\end{array}$ & $\begin{array}{l}0.21 * \\
(0.06)\end{array}$ & $\begin{array}{l}0.77 * \\
(0.06)\end{array}$ & $\begin{array}{l}0.91 * \\
(0.07)\end{array}$ & $\begin{array}{l}2.27^{*} \\
(0.14)\end{array}$ & $\begin{array}{l}1.97 * \\
(0.11)\end{array}$ \\
\hline urban & & $\begin{array}{l}-0.33 * \\
(0.05)\end{array}$ & & $\begin{array}{c}0.00 \\
(0.02)\end{array}$ & & $\begin{array}{l}0.74 * \\
(0.01)\end{array}$ & & $\begin{array}{l}-1.07 * \\
(0.03)\end{array}$ \\
\hline Other controls & No & Yes & No & Yes & No & Yes & No & Yes \\
\hline$R$-squared & 0.0003 & 0.0332 & 0.0000 & 0.0233 & 0.0001 & 0.0401 & 0.0004 & 0.0244 \\
\hline
\end{tabular}

Note: Clustered standard errors for the destination day of the week, hour of the day, year of call and urban.

Standard errors in parentheses $=$ " $* \mathrm{p}<0.01 "$ 
Table 5: Total Response Time, Time to Scene, Scene Time and Transport Time for Rural Ambulance Calls $(\mathrm{N}=2,617,189)$

\begin{tabular}{lcccccccc}
\hline & \multicolumn{2}{c}{ Total Response } & \multicolumn{2}{c}{ Time to Scene } & \multicolumn{2}{c}{ Scene Time } & \multicolumn{2}{c}{ Transport Time } \\
\hline $\begin{array}{l}\text { Independent } \\
\text { variables }\end{array}$ & $(1)$ & $(2)$ & $(3)$ & $(4)$ & $(5)$ & $(6)$ & $(7)$ & $(8)$ \\
\hline Constant & $34.98^{*}$ & $33.71^{*}$ & $7.72^{*}$ & $8.55^{*}$ & $14.87^{*}$ & $10.80^{*}$ & $12.39^{*}$ & $14.36^{*}$ \\
& $(0.05)$ & $(0.15)$ & $(0.02)$ & $(0.05)$ & $(0.01)$ & $(0.05)$ & $(0.04)$ & $(0.12)$ \\
year*hospital & $15.66^{*}$ & $15.67^{*}$ & -0.15 & -0.13 & $1.69^{*}$ & $1.84^{*}$ & $14.12^{*}$ & $13.96^{*}$ \\
close & $(0.43)$ & $(0.44)$ & $(0.13)$ & $(0.14)$ & $(0.19)$ & $(0.19)$ & $(0.34)$ & $(0.34)$ \\
& -0.07 & -0.05 & 0.03 & $0.06^{*}$ & $0.05^{*}$ & 0.01 & $-0.16^{*}$ & $-0.12^{*}$ \\
year & $(0.06)$ & $(0.05)$ & $(0.02)$ & $(0.02)$ & $(0.02)$ & $(0.01)$ & $(0.05)$ & $(0.04)$ \\
& $2.09^{*}$ & 0.48 & $0.55^{*}$ & $-0.33^{*}$ & -0.28 & $-0.44^{*}$ & $1.82^{*}$ & $1.24^{*}$ \\
hospital close & $(0.34)$ & $(0.32)$ & $(0.10)$ & $(0.11)$ & $(0.12)$ & $(0.12)$ & $(0.27)$ & $(0.25)$ \\
& No & Yes & No & Yes & No & Yes & No & Yes \\
Other controls & 0.0018 & 0.0280 & 0.0000 & 0.0301 & 0.0001 & 0.0313 & 0.0024 & 0.0256 \\
$R$-squared & &
\end{tabular}

Note: Clustered standard errors for the destination day of the week, hour of the day, year of call and urban.

Standard errors in parentheses $=$ "* $\mathrm{p}<0.01 "$

Table 6: Total Response Time, Time to Scene, Scene Time and Transport Time for Urban Ambulance Calls $(\mathrm{N}=11,161,907)$

\begin{tabular}{lcccccccc}
\hline & \multicolumn{2}{c}{ Total Response } & \multicolumn{2}{c}{ Time to Scene } & \multicolumn{2}{c}{ Scene Time } & \multicolumn{2}{c}{ Transport Time } \\
\hline $\begin{array}{l}\text { Independent } \\
\text { variables }\end{array}$ & $(1)$ & $(2)$ & $(3)$ & $(4)$ & $(5)$ & $(6)$ & $(7)$ & $(8)$ \\
\hline Constant & $33.75^{*}$ & $29.79^{*}$ & $7.57^{*}$ & $7.08^{*}$ & $15.26^{*}$ & $9.92^{*}$ & $10.91^{*}$ & $12.79^{*}$ \\
& $(0.03)$ & $(0.07)$ & $(0.01)$ & $(0.03)$ & $(0.01)$ & $(0.05)$ & $(0.02)$ & $(0.07)$ \\
year*hospital & $-1.41^{*}$ & $-0.79^{*}$ & $-0.68^{*}$ & $-0.51^{*}$ & $-0.55^{*}$ & $-0.55^{*}$ & -0.18 & 0.27 \\
close & $(0.34)$ & $(0.29)$ & $(0.08)$ & $(0.09)$ & $(0.16)$ & $(0.14)$ & $(0.20)$ & $(0.19)$ \\
& 0.08 & $0.35^{*}$ & $0.04^{*}$ & $0.10^{*}$ & $0.06^{*}$ & $0.12^{*}$ & -0.01 & $0.12^{*}$ \\
year & $(0.03)$ & $(0.02)$ & $(0.01)$ & $(0.01)$ & $(0.01)$ & $(0.01)$ & $(0.03)$ & $(0.02)$ \\
& $3.79^{*}$ & $3.77^{*}$ & $0.36^{*}$ & $0.33^{*}$ & $1.09^{*}$ & $1.39^{*}$ & $2.35^{*}$ & $2.05^{*}$ \\
hospital close & $(0.22)$ & $(0.20)$ & $(0.07)$ & $(0.07)$ & $(0.07)$ & $(0.07)$ & $(0.15)$ & $(0.13)$ \\
& No & Yes & No & Yes & No & Yes & No & Yes \\
Other controls & 0.0002 & 0.0393 & 0.0000 & 0.0235 & 0.0001 & 0.0446 & 0.0002 & 0.0265 \\
$R$-squared & N & &
\end{tabular}

Note: Clustered standard errors for the destination day of the week, hour of the day, year of call and urban.

Standard errors in parentheses $=$ "** $\mathrm{p}<0.01 "$ 
Table 7: Total Response Time, Time to Scene, Scene Time and Transport Time for Medicare-Eligible Patients for All Ambulance Calls $(\mathrm{N}=5,573,997)$

\begin{tabular}{|c|c|c|c|c|c|c|c|c|}
\hline \multirow[b]{2}{*}{$\begin{array}{l}\text { Independent } \\
\text { variables }\end{array}$} & \multicolumn{2}{|c|}{$\begin{array}{c}\text { Total Response } \\
\text { Time } \\
\end{array}$} & \multicolumn{2}{|c|}{ Time to Scene } & \multicolumn{2}{|c|}{ Scene Time } & \multicolumn{2}{|c|}{ Transport Time } \\
\hline & (1) & (2) & (3) & (4) & (5) & (6) & (7) & (8) \\
\hline Constant & $\begin{array}{c}35.40^{*} \\
(0.03)\end{array}$ & $\begin{array}{c}40.67^{*} \\
(0.18)\end{array}$ & $\begin{array}{l}7.71 * \\
(0.01)\end{array}$ & $\begin{array}{l}8.22 * \\
(0.05)\end{array}$ & $\begin{array}{l}16.72 * \\
(0.02)\end{array}$ & $\begin{array}{c}12.93^{*} \\
(0.06)\end{array}$ & $\begin{array}{l}10.97^{*} \\
(0.03)\end{array}$ & $\begin{array}{c}19.53 * \\
(0.12)\end{array}$ \\
\hline $\begin{array}{l}\text { year*hospital } \\
\text { close }\end{array}$ & $4.78 *$ & $4.35^{*}$ & $-0.67^{*}$ & $-0.74 *$ & $0.53 *$ & $0.36^{*}$ & $4.93 *$ & $4.73 *$ \\
\hline & $(0.39)$ & $(0.38)$ & $(0.10)$ & $(0.10)$ & $(0.14)$ & $(0.14)$ & $(0.31)$ & $(0.30)$ \\
\hline year & $\begin{array}{l}0.29 * \\
(0.03)\end{array}$ & $\begin{array}{l}0.45 * \\
(0.02)\end{array}$ & $\begin{array}{l}0.05^{*} \\
(0.01)\end{array}$ & $\begin{array}{l}0.10 * \\
(0.01)\end{array}$ & $\begin{array}{l}0.18^{*} \\
(0.02)\end{array}$ & $\begin{array}{l}0.22^{*} \\
(0.01)\end{array}$ & $\begin{array}{c}0.06 \\
(0.03)\end{array}$ & $\begin{array}{l}0.13^{*} \\
(0.02)\end{array}$ \\
\hline hospital close & $\begin{array}{l}3.64 * \\
(0.22)\end{array}$ & $\begin{array}{l}3.16^{*} \\
(0.22)\end{array}$ & $\begin{array}{l}0.60 * \\
(0.08)\end{array}$ & $\begin{array}{l}0.33 * \\
(0.08)\end{array}$ & $\begin{array}{l}0.76^{*} \\
(0.09)\end{array}$ & $\begin{array}{l}0.81^{*} \\
(0.10)\end{array}$ & $\begin{array}{l}2.27 * \\
(0.16)\end{array}$ & $\begin{array}{l}2.02 * \\
(0.15)\end{array}$ \\
\hline urban & & $\begin{array}{l}0.72 * \\
(0.05)\end{array}$ & & $\begin{array}{l}0.18^{*} \\
(0.02)\end{array}$ & & $\begin{array}{l}1.23 * \\
(0.02)\end{array}$ & & $\begin{array}{c}-0.69 * \\
(0.04)\end{array}$ \\
\hline Other controls & No & Yes & No & Yes & No & Yes & No & Yes \\
\hline$R$-squared & 0.0007 & 0.0297 & 0.0000 & 0.0274 & 0.0002 & 0.0137 & 0.0009 & 0.0258 \\
\hline
\end{tabular}

Table 8: Total Response Time, Time to Scene, Scene Time and Transport Time for MedicareEligible Patients for Rural Ambulance Calls (N=1,204,171)

\begin{tabular}{|c|c|c|c|c|c|c|c|c|}
\hline \multirow[b]{2}{*}{$\begin{array}{l}\text { Independent } \\
\text { variables }\end{array}$} & \multicolumn{2}{|c|}{$\begin{array}{c}\text { Total Response } \\
\text { Time }\end{array}$} & \multicolumn{2}{|c|}{ Time to Scene } & \multicolumn{2}{|c|}{ Scene Time } & \multicolumn{2}{|c|}{ Transport Time } \\
\hline & (1) & (2) & (3) & (4) & $(5)$ & (6) & (7) & $(8)$ \\
\hline \multirow[t]{2}{*}{ Constant } & $35.25^{*}$ & $50.44 *$ & $7.62 *$ & $10.54 *$ & $15.84^{*}$ & $14.65^{*}$ & $11.79^{*}$ & $25.25^{*}$ \\
\hline & $(0.07)$ & $(0.32)$ & $(0.02)$ & $(0.08)$ & $(0.02)$ & $(0.09)$ & $(0.06)$ & $(0.26)$ \\
\hline \multirow{2}{*}{$\begin{array}{l}\text { year*hospital } \\
\text { close }\end{array}$} & $17.64 *$ & $17.62 *$ & -0.16 & -0.19 & $2.18^{*}$ & $2.27^{*}$ & $15.62 *$ & $15.55^{*}$ \\
\hline & $(0.59)$ & $(0.60)$ & $(0.20)$ & $(0.21)$ & $(0.26)$ & $(0.27)$ & $(0.45)$ & $(0.44)$ \\
\hline \multirow[t]{2}{*}{ year } & 0.15 & 0.12 & $0.06^{*}$ & $0.09 *$ & $0.15^{*}$ & $0.12^{*}$ & -0.06 & -0.08 \\
\hline & $(0.07)$ & $(0.06)$ & $(0.02)$ & $(0.02)$ & $(0.02)$ & $(0.02)$ & $(0.06)$ & $(0.04)$ \\
\hline \multirow[t]{2}{*}{ hospital close } & $2.81^{*}$ & $1.31^{*}$ & $0.87^{*}$ & 0.19 & -0.18 & -0.36 & $2.13^{*}$ & $1.48^{*}$ \\
\hline & $(0.44)$ & $(0.44)$ & $(0.14)$ & $(0.15)$ & $(0.16)$ & $(0.17)$ & $(0.34)$ & $(0.32)$ \\
\hline Other controls & No & Yes & No & Yes & No & Yes & No & Yes \\
\hline$R$-squared & 0.0025 & 0.0391 & 0.0001 & 0.0293 & 0.0003 & 0.0172 & 0.0029 & 0.0366 \\
\hline
\end{tabular}


Table 9: Total Response Time, Time to Scene, Scene Time and Transport Time for MedicareEligible Patients for Urban Ambulance Calls $(\mathrm{N}=4,369,826)$

\begin{tabular}{|c|c|c|c|c|c|c|c|c|}
\hline \multirow[b]{2}{*}{$\begin{array}{l}\text { Independent } \\
\text { variables }\end{array}$} & \multicolumn{2}{|c|}{$\begin{array}{l}\text { Total Response } \\
\text { Time } \\
\end{array}$} & \multicolumn{2}{|c|}{ Time to Scene } & \multicolumn{2}{|c|}{ Scene Time } & \multicolumn{2}{|c|}{ Transport Time } \\
\hline & (1) & (2) & (3) & (4) & (5) & (6) & (7) & (8) \\
\hline Constant & $\begin{array}{l}35.44 * \\
(0.03)\end{array}$ & $\begin{array}{l}38.75^{*} \\
(0.13)\end{array}$ & $\begin{array}{l}7.73^{*} \\
(0.01)\end{array}$ & $\begin{array}{l}7.78^{*} \\
(0.05)\end{array}$ & $\begin{array}{l}16.97^{*} \\
(0.01)\end{array}$ & $\begin{array}{l}13.78^{*} \\
(0.07)\end{array}$ & $\begin{array}{l}10.74^{*} \\
(0.02)\end{array}$ & $\begin{array}{l}17.19^{*} \\
(0.09)\end{array}$ \\
\hline $\begin{array}{l}\text { year*hospit } \\
\text { al close }\end{array}$ & $0.96^{*}$ & 0.49 & $-0.80^{*}$ & $-0.89 *$ & -0.12 & -0.36 & $1.88^{*}$ & $1.74 *$ \\
\hline & $(0.36)$ & $(0.33)$ & $(0.11)$ & $(0.12)$ & $(0.17)$ & $(0.16)$ & $(0.27)$ & $(0.27)$ \\
\hline year & $\begin{array}{l}0.32^{*} \\
(0.03)\end{array}$ & $\begin{array}{l}0.52^{*} \\
(0.02)\end{array}$ & $\begin{array}{l}0.05^{*} \\
(0.01)\end{array}$ & $\begin{array}{l}0.10^{*} \\
(0.01)\end{array}$ & $\begin{array}{l}0.17^{*} \\
(0.01)\end{array}$ & $\begin{array}{l}0.24^{*} \\
(0.01)\end{array}$ & $\begin{array}{l}0.11^{*} \\
(0.03)\end{array}$ & $\begin{array}{l}0.18^{*} \\
(0.02)\end{array}$ \\
\hline $\begin{array}{l}\text { hospital } \\
\text { close }\end{array}$ & $\begin{array}{l}3.98^{*} \\
(0.25)\end{array}$ & $\begin{array}{l}3.69^{*} \\
(0.24)\end{array}$ & $\begin{array}{l}0.51^{*} \\
(0.10)\end{array}$ & $\begin{array}{l}0.35^{*} \\
(0.10)\end{array}$ & $\begin{array}{l}1.22^{*} \\
(0.11)\end{array}$ & $\begin{array}{l}1.32^{*} \\
(0.12)\end{array}$ & $\begin{array}{l}2.25^{*} \\
(0.18)\end{array}$ & $\begin{array}{l}2.02 * \\
(0.16)\end{array}$ \\
\hline $\begin{array}{l}\text { Other } \\
\text { controls }\end{array}$ & No & Yes & No & Yes & No & Yes & No & Yes \\
\hline$R$-squared & 0.0004 & 0.0327 & 0.0000 & 0.0301 & 0.0002 & 0.0118 & 0.0004 & 0.0256 \\
\hline
\end{tabular}

Note: Clustered standard errors for the destination day of the week, hour of the day, year of call and urban.

Standard errors in parentheses $=$ "** $\mathrm{p}<0.01 "$ 


\section{Appendix Tables}

Appendix Table A1: Total Response Time in an Ambulance by Match Year for All Zip Codes

\begin{tabular}{lcccc}
\hline Independent variables & 2011 & 2012 & 2013 & 2014 \\
\hline Constant & $31.11^{*}$ & $30.24^{*}$ & $29.18^{*}$ & $31.71^{*}$ \\
year*hospital close & $(0.18)$ & $(0.13)$ & $(0.16)$ & $(0.12)$ \\
& $5.61^{*}$ & $2.62^{*}$ & 1.07 & $1.04^{*}$ \\
year & $(0.63)$ & $(0.34)$ & $(0.54)$ & $(0.36)$ \\
& $0.19^{*}$ & 0.09 & $0.38^{*}$ & $0.40^{*}$ \\
hospital close & $(0.06)$ & $(0.05)$ & $(0.05)$ & $(0.04)$ \\
& $1.87^{*}$ & $1.30^{*}$ & $1.23^{*}$ & $6.88^{*}$ \\
urban & $(0.23)$ & $(0.22)$ & $(0.40)$ & $(0.28)$ \\
& $0.40^{*}$ & $-0.77^{*}$ & $-0.42^{*}$ & $-0.26^{*}$ \\
Other controls & $(0.07)$ & $(0.07)$ & $(0.09)$ & $(0.07)$ \\
R-squared & Yes & Yes & Yes & Yes \\
Observations & 0.0216 & 0.0370 & 0.0385 & 0.0374 \\
\hline
\end{tabular}

Note: Clustered standard errors for the destination day of the week, hour of the day, year of call and urban.

Standard errors in parentheses $=" * \mathrm{p}<0.01 "$

Appendix Table A2: Total Response Time in an Ambulance by Match Year for Rural Zip Codes

\begin{tabular}{lcccc}
\hline Independent variables & 2011 & 2012 & 2013 & 2014 \\
\hline Constant & $33.06^{*}$ & $35.27^{*}$ & $32.46^{*}$ & $34.97^{*}$ \\
& $(0.31)$ & $(0.23)$ & $(0.29)$ & $(0.21)$ \\
year*hospital close & $7.46^{*}$ & $12.90^{*}$ & $20.27^{*}$ & $17.25^{*}$ \\
year & $(0.79)$ & $(0.74)$ & $(0.57)$ & $(1.03)$ \\
& 0.16 & 0.15 & $0.53^{*}$ & $-0.65^{*}$ \\
hospital close & $(0.13)$ & $(0.12)$ & $(0.16)$ & $(0.11)$ \\
& $-4.94^{*}$ & $2.72^{*}$ & -0.62 & 0.63 \\
Other controls & $(0.51)$ & $(0.62)$ & $(0.48)$ & $(0.74)$ \\
Observations & Yes & Yes & Yes & Yes \\
R-squared & 0.0242 & 0.0310 & 0.0329 & 0.0308 \\
\hline
\end{tabular}

Note: Clustered standard errors for the destination day of the week, hour of the day, year of call and urban.

Standard errors in parentheses $=" * \mathrm{p}<0.01 "$ 
Appendix Table A3: Total Response Time in an Ambulance by Match Year for Urban Zip Codes

\begin{tabular}{lcccc}
\hline Independent variables & 2011 & 2012 & 2013 & 2014 \\
\hline Constant & $30.93^{*}$ & $28.34^{*}$ & $28.14^{*}$ & $30.82^{*}$ \\
& $(0.15)$ & $(0.09)$ & $(0.15)$ & $(0.10)$ \\
year*hospital close & $10.52^{*}$ & $1.42^{*}$ & $-6.91^{*}$ & -0.56 \\
& $(1.55)$ & $(0.26)$ & $(0.46)$ & $(0.36)$ \\
year & $0.20^{*}$ & 0.06 & $0.37^{*}$ & $0.58^{*}$ \\
& $(0.06)$ & $(0.04)$ & $(0.04)$ & $(0.04)$ \\
hospital close & $2.78^{*}$ & 0.18 & $5.83^{*}$ & $7.65^{*}$ \\
& $(0.24)$ & $(0.21)$ & $(0.42)$ & $(0.28)$ \\
Other controls & Yes & Yes & Yes & Yes \\
R-squared & 0.0259 & 0.0463 & 0.0452 & 0.0425 \\
Observations & $1,390,644$ & $2,977,827$ & $2,008,537$ & $4,784,899$ \\
\hline
\end{tabular}

Note: Clustered standard errors for the destination day of the week, hour of the day, year of call and urban.

Standard errors in parentheses $=" * \mathrm{p}<0.01 "$

Appendix Table A4: Falsification Test for All Zip Codes ( $\mathrm{N}=5,833,610)$

\begin{tabular}{|c|c|c|c|c|c|c|c|c|}
\hline & \multicolumn{2}{|c|}{$\begin{array}{l}\text { Total Response } \\
\text { Time }\end{array}$} & \multicolumn{2}{|c|}{ Time to Scene } & \multicolumn{2}{|c|}{ Scene Time } & \multicolumn{2}{|c|}{ Transport Time } \\
\hline & (1) & (2) & (3) & (4) & (5) & (6) & (7) & (8) \\
\hline \multirow[t]{2}{*}{ Constant } & $34.18^{*}$ & $31.89^{*}$ & $7.61 *$ & $7.48 *$ & $15.18 *$ & $10.33 *$ & $11.39 *$ & $14.08^{*}$ \\
\hline & $(0.03)$ & $(0.10)$ & $(0.01)$ & $(0.04)$ & $(0.01)$ & $(0.03)$ & $(0.03)$ & $(0.07)$ \\
\hline \multirow[t]{2}{*}{ year*hospital close } & $7.69^{*}$ & $6.32 *$ & $0.91 *$ & 0.32 & $2.76^{*}$ & $2.82 *$ & $4.02 *$ & $3.18^{*}$ \\
\hline & $(0.41)$ & $(0.41)$ & $(0.14)$ & $(0.14)$ & $(0.16)$ & $(0.16)$ & $(0.26)$ & $(0.25)$ \\
\hline \multirow[t]{2}{*}{ year } & $-0.54 *$ & -0.02 & $-0.10^{*}$ & 0.02 & -0.02 & $0.10^{*}$ & $-0.42 *$ & $-0.14 *$ \\
\hline & $(0.05)$ & $(0.04)$ & $(0.02)$ & $(0.02)$ & $(0.02)$ & $(0.01)$ & $(0.04)$ & $(0.03)$ \\
\hline \multirow[t]{2}{*}{ hospital close } & $-1.39 *$ & $-1.27 *$ & 0.18 & -0.07 & $-1.53 *$ & $-1.17 *$ & -0.04 & -0.03 \\
\hline & $(0.30)$ & $(0.28)$ & $(0.11)$ & $(0.11)$ & $(0.11)$ & $(0.11)$ & $(0.18)$ & $(0.17)$ \\
\hline \multirow[t]{2}{*}{ urban } & & $-0.49 *$ & & -0.02 & & $0.67 *$ & & $-1.15^{*}$ \\
\hline & & $(0.06)$ & & $(0.02)$ & & $(0.02)$ & & $(0.04)$ \\
\hline Other controls & No & Yes & No & Yes & No & Yes & No & Yes \\
\hline$R$-squared & 0.0005 & 0.0325 & 0.0001 & 0.0249 & 0.0001 & 0.0404 & 0.0005 & 0.0227 \\
\hline
\end{tabular}

Note: Clustered standard errors for the destination day of the week, hour of the day, year of call and urban.

Standard errors in parentheses $=$ “* $\mathrm{p}<0.01 "$ 
Appendix Table A5: Falsification Test for Rural Zip Codes ( $\mathrm{N}=1,125,039)$

\begin{tabular}{lcccccccc}
\hline & \multicolumn{2}{c}{ Total Response Time } & \multicolumn{2}{c}{ Time to Scene } & \multicolumn{2}{c}{ Scene Time } & \multicolumn{2}{c}{ Transport Time } \\
\hline Constant & $(1)$ & $(2)$ & $(3)$ & $(4)$ & $(5)$ & $(6)$ & $(7)$ & $(8)$ \\
& $35.00^{*}$ & $35.92^{*}$ & $7.69^{*}$ & $8.98^{*}$ & $14.77^{*}$ & $11.00^{*}$ & $12.54^{*}$ & $15.94^{*}$ \\
year*hospital close & $(0.08)$ & $(0.18)$ & $(0.02)$ & $(0.06)$ & $(0.02)$ & $(0.05)$ & $(0.07)$ & $(0.15)$ \\
& $-3.00^{*}$ & $-2.22^{*}$ & $-0.75^{*}$ & $-1.41^{*}$ & 0.02 & 0.57 & $-2.27^{*}$ & -1.38 \\
year & $(0.76)$ & $(0.80)$ & $(0.29)$ & $(0.30)$ & $(0.31)$ & $(0.32)$ & $(0.57)$ & $(0.59)$ \\
& -0.07 & -0.06 & -0.05 & -0.03 & $0.29^{*}$ & $0.19^{*}$ & $-0.31^{*}$ & $-0.23^{*}$ \\
hospital close & $(0.11)$ & $(0.10)$ & $(0.03)$ & $(0.03)$ & $(0.02)$ & $(0.02)$ & $(0.10)$ & $(0.07)$ \\
& $3.80^{*}$ & $1.99^{*}$ & $1.20^{*}$ & $0.77^{*}$ & 0.06 & -0.34 & $2.54^{*}$ & $1.55^{*}$ \\
Other controls & $(0.66)$ & $(0.71)$ & $(0.26)$ & $(0.26)$ & $(0.25)$ & $(0.27)$ & $(0.50)$ & $(0.52)$ \\
R-squared & No & Yes & No & Yes & No & Yes & No & Yes \\
\hline & 0.0000 & 0.0250 & 0.0001 & 0.0327 & 0.0003 & 0.0349 & 0.0001 & 0.0216 \\
\hline
\end{tabular}

Note: Clustered standard errors for the destination day of the week, hour of the day, year of call and urban.

Standard errors in parentheses $=$ "* $\mathrm{p}<0.01 "$

Appendix Table A6: Falsification Test for Urban Zip Codes $(\mathrm{N}=4,708,571)$

\begin{tabular}{|c|c|c|c|c|c|c|c|c|}
\hline & \multicolumn{2}{|c|}{ Total Response Time } & \multicolumn{2}{|c|}{ Time to Scene } & \multicolumn{2}{|c|}{ Scene Time } & \multicolumn{2}{|c|}{ Transport Time } \\
\hline & (1) & (2) & (3) & (4) & (5) & (6) & (7) & $(8)$ \\
\hline Constant & $\begin{array}{l}33.93^{*} \\
(0.04)\end{array}$ & & $\begin{array}{l}7.59^{*} \\
(0.02)\end{array}$ & & $\begin{array}{l}15.30^{*} \\
(0.01)\end{array}$ & & $\begin{array}{l}11.04 * \\
(0.03)\end{array}$ & $\begin{array}{c}12.49^{*} \\
(0.06)\end{array}$ \\
\hline & $11.26^{*}$ & $10.55^{*}$ & $1.44^{*}$ & $1.02 *$ & $3.75^{*}$ & $4.04 *$ & $6.07^{*}$ & $5.49 *$ \\
\hline & $(0.36)$ & $(0.36)$ & $(0.15)$ & $(0.15)$ & $(0.18)$ & $(0.18)$ & $(0.23)$ & $(0.22)$ \\
\hline year & $\begin{array}{c}-0.56^{*} \\
(0.05)\end{array}$ & $\begin{array}{l}-0.03 \\
(0.05)\end{array}$ & $\begin{array}{c}-0.10^{*} \\
(0.02)\end{array}$ & $\begin{array}{c}0.03 \\
(0.02)\end{array}$ & $\begin{array}{c}-0.12^{*} \\
(0.02)\end{array}$ & $\begin{array}{l}0.09^{*} \\
(0.01)\end{array}$ & $\begin{array}{c}-0.34 * \\
(0.04)\end{array}$ & $\begin{array}{c}-0.15^{*} \\
(0.03)\end{array}$ \\
\hline hospital close & $\begin{array}{c}-2.84 * \\
(0.27)\end{array}$ & $\begin{array}{c}-2.81 * \\
(0.27)\end{array}$ & $\begin{array}{c}-0.10 \\
(0.11)\end{array}$ & $\begin{array}{r}-0.41^{*} \\
(0.11)\end{array}$ & $\begin{array}{c}-1.99^{*} \\
(0.11)\end{array}$ & $\begin{array}{r}-1.65^{*} \\
(0.12)\end{array}$ & $\begin{array}{c}-0.74 * \\
(0.16)\end{array}$ & $\begin{array}{c}-0.76^{*} \\
(0.15)\end{array}$ \\
\hline Other c & No & Yes & No & Yes & No & Yes & No & Yes \\
\hline$R$-squared & 0.0007 & 0.0380 & 0.0001 & 0.0256 & 0.0002 & 0.0443 & 0.0006 & 0.0239 \\
\hline
\end{tabular}

Note: Clustered standard errors for the destination day of the week, hour of the day, year of call and urban.

Standard errors in parentheses $=$ “* $\mathrm{p}<0.01 "$ 